Article

\title{
Business Models for Demand Response: Exploring the Economic Limits for Small- and Medium-Sized Prosumers
}

\author{
Guntram Pressmair*(D), Christof Amann and Klemens Leutgöb \\ E7 Energy Innovation \& Engineering, 1020 Vienna, Austria; christof.amann@e-sieben.at (C.A.); \\ klemens.leutgob@e-sieben.at (K.L.) \\ * Correspondence: guntram.pressmair@e-sieben.at
}

check for updates

Citation: Pressmair, G.; Amann, C.; Leutgöb, K. Business Models for Demand Response: Exploring the Economic Limits for Small- and Medium-Sized Prosumers. Energies 2021, 14, 7085. https://doi.org/ $10.3390 /$ en14217085

Academic Editor: Dimitrios I. Doukas

Received: 5 October 2021

Accepted: 26 October 2021

Published: 29 October 2021

Publisher's Note: MDPI stays neutral with regard to jurisdictional claims in published maps and institutional affiliations.

Copyright: (c) 2021 by the authors. Licensee MDPI, Basel, Switzerland. This article is an open access article distributed under the terms and conditions of the Creative Commons Attribution (CC BY) license (https:/ / creativecommons.org/licenses/by/ $4.0 /)$.

\begin{abstract}
The European energy transition increasingly requires flexibility to ensure reliable operation of the electricity system, making use of demand response, a promising concept. With technological advances in the fields of big data analysis and the internet of things, small- and medium-sized prosumers could also provide flexibility services through aggregators. A lot of conceptual work has been conducted recently to formulate business models in this context, but their viability still remains unclear. In this paper, a quantitative validation is conducted of two business models that are frequently proposed in the scientific discussion. The aim of this work is to explore the economic limits of these business models and show under which conditions they can be profitable for smalland medium-sized prosumers. For this purpose, a multi-level contribution margin calculation for several scenarios, customer segments and target markets is conducted. The results show that the profitability for the participation of small loads is still very low under current market conditions. Especially for household consumers, transaction costs are too high to be covered by the revenues. Considering the quantitative results, in the future profitable business cases can only be expected for medium-sized tertiary consumers.
\end{abstract}

Keywords: business model; demand response; flexibility; prosumers; economic assessment

\section{Introduction \\ 1.1. Background}

The widespread roll out of decentralised and fluctuating renewable energy generation poses challenges to the reliability of the electricity network, requiring increased flexibility in the system. Flexibility can be provided by generators, but also by consumers, which is commonly referred to as Demand Response (DR). DR can be understood as "voluntary changes by end-consumers of their usual electricity use patterns-in response to market signals [ ... ]" [1]. In some countries, DR schemes have a long tradition, whereas in others the efforts to develop DR programmes start from zero [2].

In Europe, EU policies regarding DR have evolved significantly in the last decade, laying the foundation for a fully market-based approach towards DR with a focus on enabling end-users to participate more actively in electricity markets. In particular, in the Energy Efficiency Directive of 2012 [3], Art. 15.8 encourages demand response either through direct market participation or aggregation [4]. The more recent Clean Energy Package further develops the market design by setting new measures for market access of DR, dynamic pricing offers, the role of aggregators and also energy communities [5].

Beyond the European context, DR has been supported in energy policies, mainly as a tool to foster grid reliability and increase the share of renewable generation. In the United States, DR has a long tradition for industrial facilities, but dynamic pricing is also commonly available. The discussion has recently gained momentum with the US Order 2222 opening up all organised wholesale markets to aggregators of distributed energy resources [6]. In Australia, trials have analysed the participation of even residential distributed energy resources in national wholesale markets such as in the virtual power plant demonstrator in 
Western Australia [7]. Another example is China, where specific demand-side management policies introduce DR programs in the monopolized national energy market [8]. For an in-depth review on DR initiatives and products on an international level, one can refer to [2].

In general, DR has been traditionally only economically viable for energy intensive industrial facilities with large-scale loads that can be ramped up or down according to system needs. With technological advances in the field of big data analysis and the internet of things (IoT), small- and medium-sized consumers and prosumers could also provide their flexibility as services. Residential consumers have a very limited flexibility potential as individuals, but theoretically represent a large source of flexibility as an aggregated pool [9]. However, the residential sector in particular faces major challenges due to its limited business case, the issue that hardware and software infrastructure takes long to be upgraded and harmonised and finally because the energy consumption is very much driven by the behaviour of individuals and their specific preferences [10].

This research has been conducted in the course of the Horizon 2020 DELTA project [11], which tackles the aim to unleash the DR potential of small and medium-sized electricity prosumers, including households, in Europe. DELTA proposes a DR management platform that distributes part of the aggregator's intelligence into lower layers of its architecture, in order to establish a more easily manageable and computationally efficient demand response solution. The project's main innovations include the DELTA Virtual Node, which is clustering customers with similar flexibility potential, and the so-called fog enabled intelligent device (FEID), a building level gateway communicating and executing DR requests at the end-users' devices.

\subsection{State of the Art on Business Model Concepts and Enabling Technologies}

Novel business models for DR in the domain of small and even residential prosumers heavily build on technologic advances of the recent years. Starting from the prosumers' premises, a widespread roll out of smart meters with bidirectional communication capabilities is required, creating a network of advanced metering infrastructure (AMI). In addition to building energy management systems (BEMS), these are the key hardware requirements from the prosumers' perspective. Furthermore, efficient and reliable communication infrastructure with low latency and a moderate bandwidth is needed [12]. In order to achieve a valid business case, on top of this key infrastructure, innovative data-driven analytic methods need to be deployed. A vital element for DR service providers is customer targeting, which means to select the right customer with a suitable flexibility potential. The authors of [13] propose a scalable and data-driven approach for DR program targeting, utilizing data from individual smart meters and making customer recruitment more efficient. One step further, in [14] a methodology is presented to define the operational DR potential (consisting of DR duration, impact on customer comfort and indoor temperature, etc.), including consumption behaviour learning. Finally, authors of [15] aim at acquiring a better understanding of how residential DR participants respond to DR events. A range of machine learning approaches is used to model the relationship between a household's response and specific household-related features.

The scientific literature is rich in conceptual work on business models (BMs) for demand response, especially with regards to aggregation of smaller loads. A comprehensive tool for formulating such BMs has been proposed in [16], where the typical business model canvas from [17] has been further developed to the demand response business model canvas (DRBMC). A common way to categorise DR BMs is related to their type of revenue streams. A clear differentiation is given by [18]. According to that, in explicit DR (also called "incentive-based") prosumers receive direct payments to change their consumption upon request. Aggregated changes in load are traded in electricity markets such as the balancing or wholesale market. In contrast, in implicit DR (also called "price based") prosumers are exposed to time-varying electricity prices (or even time-varying network tariffs) and can react to those price signals by changing their consumption behaviour. 
Other than in explicit DR, participation in implicit DR means no commitment to dispatch any flexibility.

In the context of explicit DR, flexibility can be traded on various markets. Characterising these markets and the respective flexibility products, authors of [19] differentiate based on the purpose in the network hierarchy. This is flexibility at the transmission grid, flexibility at the distribution grid and flexibility for the distribution grid. In [20] a classification is given based on an extensive literature review. This includes business models from the perspectives of system operation, generation, transmission/distribution, energy retailing and load. A very coherent taxonomy of flexibility markets for explicit DR services is given by [21]. It differentiates flexibility services for constraint management (e.g., congestion management, voltage control) either on TSO or DSO level, adequacy services (e.g., capacity markets), wholesale markets (e.g., day-ahead and intraday portfolio optimisation) and balancing services (e.g., primary, secondary and tertiary frequency control). A fundamental question for the design of an explicit DR business model is, if the DR provision is integrated with or dissociated from power supply, as discussed in [22]. Integrated means that the prosumer's energy supplier and the DR aggregator are under the same balance responsible party (BRP). In the current market structure this approach is less complex to be implemented since there are fewer stakeholders involved. From a business perspective, it is also argued in [23] that the supplier is in the best position for taking the role of a DR aggregator since they already have a strong connection to both the electricity market and the end-users. However, the integrated model restricts the action of other players who are independent from the supplier. This can reduce market flexibility and decrease attractiveness of DR in some markets. In contrast, dissociated means that an independent aggregator, which is detached from the supplier's BRP, is activating and trading flexibility. In the US this is referred to as a "curtailment service provider" which is a relatively well-established role on the market [24]. Independent aggregation opens up a level playing field for many stakeholders, but requires clear processes for settling a fair compensation between the aggregator and the supplier. This compensation is needed because of the transfer of energy between the balance groups and the additional imbalance risk caused by the aggregator. An in-depth discussion on integrated and independent aggregation is provided in [25], including various implementation models.

In implicit DR, flexibility is activated through the retail market by dynamic prices. For a supplier offering such a scheme, this creates a business model as the fluctuation in wholesale prices is (partly) passed on to the end-users. However, financial gains through flexibility can only be achieved if the end-user actively optimises its load profile according to this price structure. This could be achieved by changing the behaviour, which means that the end-user manually adapts its load profile. However, as argued by [26], if DR resources are not dispatchable by the DR aggregator or other service provider, implicit DR would activate only a small part of the total flexibility potential. Hence, shifting loads for prosumers and achieving cost savings for them could be a business model for Energy Service Companies (ESCOs), who are providers of auxiliary energy-related services for prosumers [27]. However, in the domain of energy efficiency contracting, the term "ESCo" is already well defined as a provider of contracting projects assuming a certain degree of financial risks [28]. Therefore, [29] proposes the term Flexibility Service Company (FLESCo) for this kind of service provider. As argued by [30], from a regulatory perspective implicit DR BMs are currently the most feasible ones, facing no significant legal barrier.

Finally, it should be noted that both explicit and implicit BMs are often combined with other services that are already established on the market. Coming from the domain of energy efficiency contracting, the so-called "dual service" combines explicit DR with an energy performance contracting project [31]. Furthermore, authors of [32] have sketched the BM of an "Energy Supplier 2.0" that integrates this dual service into a traditional supplier BM. Another very promising service package integrates DR services with equipment provision. This approach is often applied, especially for trials addressing residential pro- 
sumers [23]. In such a BM, the aggregator cooperates with, e.g., a heat pump manufacturer to target promising customers and ensure technical interoperability.

Besides the conceptual work on DR BMs, economic benefits for end-users and new stakeholders such as aggregators have also been analysed in recent studies. In [33], a twostage stochastic optimisation approach is proposed for supporting an aggregator active in DA wholesale energy markets and also secondary reserve markets by finding an optimal bidding strategy for participating in both markets simultaneously. The results suggest that by applying this dual strategy, costs of the aggregator and the prosumers can be reduced by $40 \%$ compared to an inflexible scenario and by $20 \%$ compared to participation in a single market. Similarly, in [34] this methodology is applied for parallel participation in the DA wholesale market and the tertiary reserve market, indicating cost reductions of $48 \%$ compared to the inflexible scenario and $21 \%$ compared to a single market strategy. In both studies, focus is put on specific DERs with a high individual flexibility potential. As a conclusion, the authors suggest that customers with EVs should be especially targeted, as they represent the main source of flexibility in this context. The authors of [35] specifically focus on battery storage systems as flexibility sources in a peer-to peer trading framework. Findings suggest that community costs can be reduced in a battery storage scenario by $20 \%$ and in a pure peer-to-peer scenario by $34 \%$ compared to an inflexible business as usual scenario. When combining both approaches, the community costs can be reduced by even $59 \%$.

What the aforementioned studies have in common is their focus on very specific distributed energy resources that promise a significant flexibility potential as an individual asset. However, as mentioned by [24], typical load assets of residential end-users in particular rather include a range of appliances with very limited flexibility potential as standalone assets. Therefore, the incremental costs for enabling DR for residential customers are considered high. As a conclusion, there seems to be a volume of untapped flexibility potential that suffers from a lack of economic viability, which is a general weakness. This is argued in [30], pointing out that residents might not have a visible monetary benefit in such BMs. This constitutes a major barrier, since the expected financial benefits are a key driver for residential end-users to participate in DR schemes [9].

\subsection{Scope and Structure of the Paper}

As highlighted in Section 1.2, projections for the limits of the economic viability of typical currently uncontrolled loads as flexibility resources are still vague. Tackling this gap of knowledge, the aim of this paper is to conduct a quantitative performance assessment of DR BMs for small- and medium-sized prosumers with a focus on load assets typically deployed in the current building stock. Against the backdrop of the conceptual work on DR BMs above, there are two main BMs that will be validated in this paper:

1. Explicit DR, also called Aggregator BM: This BM considers an aggregator that is active on the balancing market as a Balancing Service Provider (BSP) and communicates flexibility requests to the prosumers via the DELTA solution. The aggregator is assumed to be an independent one, but compensation mechanisms among the BRPs involved are neglected.

2. Implicit DR, also called FLESCO BM: The FLESCO as a service provider is responsible for shifting loads for a prosumer in order to minimise costs in a given time-of-use (ToU) pricing scheme. In a ToU scheme, the price varies a few times during the day as well as a during the year.

All BMs analysed in this work are enabled by the technology developed in the DELTA project. This includes not only the FEID, but also data-driven analytics for user clustering and flexibility forecasting. Note that this paper aims to identify potential economic viability of this BMs with a focus on the widespread replication of these BMs in Europe. Therefore, the scope of this assessment is not limited to the specific business scenarios tested at the DELTA pilot sites.

Following this approach, this paper addresses several research questions: 
- Which target segments could be profitable for the BMs?

- What are the key aspects for identifying a profitable target segment?

- What is the critical size of these target customers?

- Which market conditions need to be met to make the BMs profitable?

- Which internal conditions at the service provider need to be met to make the BM work?

- What is the contribution of technology advances?

The remainder of this paper is structured as follows: In Section 2, the methodology of the economic assessment is introduced, along with the selected prosumer target segments. Section 3 presents the results of the assessment and finally Section 4 provides a discussion of the findings and an overall outlook on DR BMs for small- and medium-sized prosumers.

\section{Methodology}

The methodology for validating the DR BMs is based on a multi-level contribution margin calculation. This is a method of cost accounting that has been adapted for this paper to consider the impact of DR-specific cost items and revenues from relevant flexibility markets. This method transparently shows which are the most critical cost elements in the DR BMs compared to the revenues that could be achieved. For the two selected BMs, this method is applied in several scenarios for the markets in Austria and the UK.

These countries have been chosen because of the different characteristics of their national electricity markets. The UK has been one of the first countries in Europe to open electricity markets for active consumer participation and therefore represents a very mature market. The competition among aggregators can be considered relatively high. In Austria, the national TSO opened up the balancing markets for DR in 2013, but the market entry barriers remain high. This means that the Austrian market for DR is still underdeveloped and competition is low [36].

For this analysis, different target segments and input assumptions are chosen, showing under which conditions a profitable business case can be expected. The results rely mainly on the following datasets:

- Market data from organised electricity markets, where flexibility can be traded: This includes wholesale day-ahead (DA) and also balancing markets.

- Cost elements: As this is an explorative business modelling approach, there are no suitable cost data available as a reference. Hence, well-founded bottom-up assumptions for the selected BMs have been formulated and validated within the DELTA consortium. This was achieved especially in close cooperation with the technical developers and pilot site managers of the project. As a result, the latest experiences gathered during the installation and deployment of the pilot sites have been fed into these assumptions.

- Other assumptions such as target segment characteristics.

In the following sub-sections, the calculation models for both BMs are described in detail.

\subsection{Aggregator BM}

For validating this BM, an aggregator is considered offering flexibility from its customers' loads on the balancing market.

For Austria, the market data of the aFRR+ market in 2020 have been retrieved from ENTSO-E [37]. According to the ENTSO-E terminology, aFRR+ is "positive automatic frequency restoration reserve", which means that either upwards generation or downwards loads are offered. In Austria, this is also referred to as positive secondary frequency response. The data used for the analysis are presented in Table A1 in Appendix A. For the UK, a slightly simplified approach has been applied regarding the market data, due to lack of availability of the same data from ENTSO-E. The British Firm Frequency Response (FFR) market has been considered for this business model. The data have been retrieved from the FFR Post Tender Reports of the year 2020 [38] for the dynamic FFR. FFR includes primary, secondary and tertiary response. However, as highlighted by National Grid [3], 
the main focus of tenderers should be on the secondary response and therefore the market prices are derived based on their offer on the secondary response market. This is also in line with the previously mentioned aFRR market used for the Austrian case. Additionally, National Grid [39] mentions that most tenderers only tender in the Availability Fee $(£ / h)$, which is the remuneration for keeping the capacity available, rather than the Response Energy Fee $(£ / \mathrm{MWh})$, which is the remuneration for the actual dispatch. This is because the energy volumes utilised are comparably small. The derived market prices used for the cost accounting are shown in Table A2.

For modelling the end-users, yearly load profiles have been obtained for each target segment to calculate the impact of the DR actions. The granularity of the time steps of the model is $30 \mathrm{~min}$. The amount of energy offered and dispatched for the needs of the balancing market are calculated through a range of factors, including:

- Share of shiftable loads: The total consumption in each time frame is multiplied by the share of shiftable loads that is available for DR. This shiftable load is generally only available at maximum $50 \%$ of the time, as the loads need to be recovered at another time.

- Besides the load shifting potential, a certain share of shedable loads has also been considered. This means that the shiftable loads need to be recovered at a later time of the day, whereas shedable loads do not need to be recovered at all. Shedable loads are generally considered to be available $100 \%$ of the time as they do not need to be recovered.

- As the balancing market consists of a two-step auction, the probability of being successful in these auctions needs to be estimated. If the capacity auction has been successful, the aggregator participates in the energy auction. The energy auction is only started if there is a request for flexibility during the specific time slice. The probability for having such a request is shown in Table A3. The probabilities of being successful are estimated with $80 \%$ for the capacity auction and $50 \%$ for the energy auction.

- As a reference, a flat energy pricing scheme is considered to compare the savings achieved with the business as usual (BaU) energy costs. Typical pricing offers for the UK and Austria have been selected. The price data and underlying assumptions are presented in Tables A4 and A5.

Finally, all input parameters for the Aggregator BM are compiled in Table 1.

Table 1. Input data Aggregator BM.

\begin{tabular}{|c|c|c|c|}
\hline Category & Item & Symbol & Comment * \\
\hline Consumption pattern & $\begin{array}{c}\text { Building type } \\
\text { Total consumption } \\
\text { Share of shiftable loads } \\
\text { Load shifting available } \\
\text { Share of shedable loads } \\
\text { Load shedding available }\end{array}$ & cons & $\begin{array}{l}\text { e.g., household, office etc. } \\
\text { kWh/year } \\
\text { share of total consumption } \\
50 \% \text { share of shiftable loads } \\
\text { share of total consumption } \\
100 \% \text { share of shedable loads }\end{array}$ \\
\hline Market Prices & Market & & aFRR+ or FFR \\
\hline Probability of Success & $\begin{array}{l}\text { in capacity auction } \\
\text { in energy auction }\end{array}$ & & $\begin{array}{l}\text { share of time slots } \\
\text { share of time slots }\end{array}$ \\
\hline Pricing Model & Remuneration for customer & rem & $\begin{array}{l}\text { share of revenue per } \\
\text { customer }\end{array}$ \\
\hline Bau Flat Pricing Scheme & $\begin{array}{l}\text { Energy price } \\
\text { Basic fee }\end{array}$ & $\begin{array}{l}P_{v} \\
P_{b}\end{array}$ & $\begin{array}{l}€ / \mathrm{kWh} \\
€ / \text { year }\end{array}$ \\
\hline Cost Structure & $\begin{array}{l}\text { Customer fixed costs } \\
\text { Aggregator fixed costs }\end{array}$ & $\begin{array}{l}C_{\text {customer }} \\
C_{a g g}\end{array}$ & $\begin{array}{l}€ / \text { year } \\
€ / \text { year }\end{array}$ \\
\hline Customer Scaling & number of customers & $n$ & number \\
\hline
\end{tabular}

${ }^{*}$ for the UK case the currency is $£$.

The actual multi-level contribution margin calculation is shown in Table 2. At first the Revenues are calculated as the sum of the revenues from contracted balancing capacity and dispatched balancing energy. CM1 can then be calculated by subtracting the remuneration 
that goes back to the consumers for their flexibility provision. In addition, the savings achieved by the customer can be calculated by comparing the revenues (and the savings from shedding) with the BaU costs for their energy supply. For calculating CM2, the customer fixed costs are subtracted and for the OP the overhead costs of the aggregator are also considered.

Table 2. Multi-level contribution margin calculation for the Aggregator BM.

\begin{tabular}{|c|c|c|c|c|}
\hline Calculation Step & Item & Symbol & Formula & Unit* \\
\hline \multirow{3}{*}{ Revenue Per Customer } & Revenue Balancing Capacity & $R_{\text {cap }}$ & & $€$ \\
\hline & Revenue Balancing Energy & $R_{e n}$ & & $€$ \\
\hline & Revenue & $R$ & $R_{\text {cap }}+R_{e n}$ & $€$ \\
\hline \multirow{5}{*}{ Contribution Margin 1} & Customer Remuneration & $S_{r e m}$ & $R * \mathrm{rem}$ & $€$ \\
\hline & Customer Savings Due to Shedding & $S_{\text {shed }}$ & & $€$ \\
\hline & Customer Savings Total & $S_{t o t}$ & $S_{\text {rem }}+S_{\text {shed }}$ & $€$ \\
\hline & Customer Savings Relative & $S_{r e l}$ & $S_{t o t} /\left(p_{b}+p_{v} *\right.$ cons $)$ & share \\
\hline & Contribution Margin 1 & $C M_{1}$ & $R-S_{\text {rem }}$ & $€$ \\
\hline \multirow{2}{*}{ Contribution Margin 2} & Customer Fixed Costs & $C_{\text {customer }}$ & & $€$ \\
\hline & Contribution Margin 2 & $\mathrm{CM}_{2}$ & $\mathrm{CM}_{1}-\mathrm{C}_{\text {customer }}$ & $€$ \\
\hline \multirow{3}{*}{ Operational Profit } & Overall Contribution Margin & $C M_{\text {tot }}$ & $C M_{2} * n$ & $€$ \\
\hline & Aggregator Fixed Costs & $C_{\text {flesco }}$ & & $€$ \\
\hline & Operational Profit & $O P$ & $C M_{t o t}-C_{a g g}$ & $€$ \\
\hline
\end{tabular}

* for the UK case the currency is $£$.

In an alternative scenario, the effect of the aggregator participating in multiple flexibility markets, not only the balancing market, is assessed. For this purpose, additionally participation in the DA wholesale electricity market is considered. Based on the actual market data of 2019 [40], the aggregator places the bids either on the aFRR+ market or the DA wholesale market. Note that this alternative scenario should show the maximum revenues that could be achieved participating on both markets, assuming that the aggregator always makes the optimal decision. In practice, market participation in both the DA wholesale and the balancing market is difficult due to regulatory constraints, as in the balancing market bids have to be submitted already for the capacity auction, whereas in the DA wholesale market there is only an energy auction.

\subsection{FLESCO BM}

For validating the FLESCO BM, market data from the DA markets of Austria and the UK have been obtained and scenarios have been calculated for each of these markets. The FLESCO as a third-party service provider is not involved in any energy trading. The FLESCO is hired by a consumer who is under a ToU supply contract. Following available market data have been obtained:

- $\quad$ Austria: One year data for the year 2019, retrieved from the ENTSO-E [40].

- UK: One year data from (July 2020-June 2021), retrieved from Nord Pool power exchange [41].

All these price data have been used to derive a synthetic ToU pricing scheme for each country with three time periods during a day: High (06:00-10:00; 17:00-22:00), Mid (10:00-17:00) and Low (22:00-06:00). To create plausible ToU prices, it is assumed that a basic fee (standing charge) and a surcharge on DA spot prices (per kWh) are added by the supplier of the ToU scheme. This is a common business model for spot market dependent pricing schemes. The supplier surcharge is defined in Table A6. The derived ToU prices (without supplier fees) are shown in Figures A2 and A3.

Again, yearly load profiles have been obtained for each target segment to simulate load profile optimisation by the FLESCO. The optimisation takes place for each day by shifting as much as possible of the shiftable load from high to low price period. Load shedding has been considered as well. Table 3 shows the input data for the cost accounting tool for the FLESCO BM. 
Table 3. Input data FLESCO BM.

\begin{tabular}{|c|c|c|c|c|}
\hline Category & & & Symbol & Comment * \\
\hline \multirow{8}{*}{$\begin{array}{l}\text { Consumption } \\
\text { Pattern }\end{array}$} & \multicolumn{2}{|c|}{ Building Type } & & e.g., household, office etc. \\
\hline & \multicolumn{2}{|c|}{ Total Consumption } & cons & $\mathrm{kWh} /$ year \\
\hline & \multicolumn{2}{|c|}{ Share of Shiftable Loads } & & share of total consumption \\
\hline & \multicolumn{2}{|c|}{ Share of Shedable Loads } & & share of total consumption \\
\hline & Spring & High/Mid/Low & & \multirow{4}{*}{ share of total consumption } \\
\hline & Summer & High/Mid/Low & & \\
\hline & Fall & High/Mid/Low & & \\
\hline & Winter & High/Mid/Low & & \\
\hline \multirow{4}{*}{ Spot Market Prices } & Spring & High/Mid/Low & & \multirow{4}{*}{$€ / \mathrm{kWh}$} \\
\hline & Summer & High/Mid/Low & & \\
\hline & Fall & High/Mid/Low & & \\
\hline & Winter & High/Mid/Low & & \\
\hline \multirow{2}{*}{$\begin{array}{l}\text { ToU pricing } \\
\text { scheme }\end{array}$} & \multicolumn{2}{|c|}{ Surcharge on Spot Price } & & $€ / \mathrm{kWh}$ \\
\hline & \multicolumn{2}{|c|}{ Basic Fee } & & $€ /$ year \\
\hline \multirow{2}{*}{$\begin{array}{l}\text { BaU flat pricing } \\
\text { scheme }\end{array}$} & \multicolumn{2}{|c|}{ Energy Price } & $p_{v}$ & $€ / \mathrm{kWh}$ \\
\hline & \multicolumn{2}{|c|}{ Basic Fee } & $p_{b}$ & $€ /$ year \\
\hline $\begin{array}{l}\text { FLESCO pricing } \\
\text { model }\end{array}$ & \multicolumn{2}{|c|}{ Remuneration for customer } & rem & $\begin{array}{l}\text { share of revenue per } \\
\text { customer }\end{array}$ \\
\hline \multirow{2}{*}{ Cost structure } & \multicolumn{2}{|c|}{ Customer fixed costs } & $C_{\text {customer }}$ & $€ /$ year \\
\hline & \multicolumn{2}{|c|}{ FLESCO fixed costs } & $C_{a g g}$ & $€ /$ year \\
\hline Customer scaling & \multicolumn{2}{|c|}{ number of customers } & $n$ & number \\
\hline
\end{tabular}

The multi-level contribution margin calculation for the FLESCO BM is shown in Table 4. The revenue for one customer is calculated by comparing the energy costs with the ToU pricing scheme for the FLESCO-optimised load profile and the BaU costs for the initial load profile in a comparable flat energy pricing scheme (fixed price per $\mathrm{kWh}$ ). CM1 of the FLESCO is then calculated by subtracting the remuneration for the customer. Note that in the cost accounting model, this step is performed as an analogue to the previous BM; however, in reality there is no remuneration paid by the FLESCO to the customer but a service fee (1-rem) is paid by the customer to the FLESCO. For calculating CM2, again, the customer fixed costs are subtracted and for the OP also the overhead costs of the FLESCO are considered.

Table 4. Multi-level contribution margin calculation for the FLESCO BM.

\begin{tabular}{|c|c|c|c|c|}
\hline Calculation Step & Item & Symbol & Formula & Unit * \\
\hline \multirow{3}{*}{ Revenue per customer } & Energy costs ToU optimised & $E_{\text {opt }}$ & & $€$ \\
\hline & Energy costs $\mathrm{BaU}$ flat & $E_{\text {flat }}$ & $p_{b}+p_{v} *$ cons & $€$ \\
\hline & Revenue & $R$ & $E_{\text {flat }}-E_{\text {opt }}$ & $€$ \\
\hline \multirow{3}{*}{ Contribution margin 1} & Customer remuneration & $S_{\text {rem }}$ & $R *$ rem & $€$ \\
\hline & Customer savings relative & $S_{\text {rel }}$ & $S_{\text {rem }} / E_{\text {flat }}$ & share \\
\hline & Contribution margin 1 & $C M_{1}$ & $R-S_{r e m}$ & $€$ \\
\hline \multirow{2}{*}{ Contribution margin 2} & Customer fixed costs & $C_{\text {customer }}$ & & $€$ \\
\hline & Contribution margin 2 & $\mathrm{CM}_{2}$ & $C M_{1}-C_{\text {customer }}$ & $€$ \\
\hline \multirow{3}{*}{ Operational profit } & Overall contribution margin & $C M_{\text {tot }}$ & $C M_{2} * n$ & $€$ \\
\hline & FLESCO fixed costs & $C_{\text {flesco }}$ & & $€$ \\
\hline & Operational profit & $O P$ & $C M_{\text {tot }}-C_{\text {flesco }}$ & $€$ \\
\hline
\end{tabular}

* for the UK case the currency is $£$.

\subsection{Target Segments and Cost Data}

The profitability of a customer for a DR scheme depends on its size (meaning the overall electricity consumption) and on the individual flexibility potential of the devices operated on-site. 
The approach of DELTA and thus of this work is to assess the flexibility potential of small loads that are currently considered uncontrolled. The DELTA FEID is designed to make them controllable and activate their flexibility. Hence, the scope of this analysis is not limited to specific flexible DERs but also addresses loads that do not have a significant flexibility potential as an individual asset. The aim is to evaluate to which extent these loads could achieve a significant flexibility potential as an aggregated pool. Therefore, the target segments have been defined by their typical consumption patterns including the load assets that are typically deployed in these user groups. The business approach is customer segment oriented, which means that user groups are connected in large scale to the DELTA pool through standardised processes. This should enable the integration of these DR BMs as add-on services for stakeholders such as energy suppliers or facility managers, for instance.

Based on that, several target segments and customer sizes have been defined for further analysis in the cost accounting model. The target segments are summarised in Table 5 and briefly described in the following paragraphs. For each segment the underlying assumptions regarding their load profiles and the expected customer fixed costs are described in detail in Appendix B. The load profiles are standard load profiles or real measured data from previous pilot projects. In order to make plausible assumptions on the customer-fixed costs, a bottom-up approach has been followed, by assigning costs for each cost element identified. Similarly, for the overhead costs of an aggregator or FLESCO, a bottom-up approach has also been applied. The resulting cost assumptions are presented in detail in Appendix B as well.

Table 5. Summary of target segments.

\begin{tabular}{cccc}
\hline Target Segment & Customer Size & $\begin{array}{c}\text { Annual } \\
\text { Consumption (kWh) }\end{array}$ & $\begin{array}{c}\text { Annual Customer } \\
\text { Fixed Costs (€) }\end{array}$ \\
\hline \multirow{2}{*}{ Household } & Couple apartment (CA) & 2000 & 80 \\
& Family apartment (FA) & 3500 & 94 \\
& Single-family house (SFH) & 5000 & 108 \\
\hline \multirow{2}{*}{ Residential Building } & Small (S) & 10,000 & 282 \\
(excl. households) & Medium (M) & 50,000 & 372 \\
& Large (L) & 200,000 & 584 \\
\hline \multirow{2}{*}{ Residential building } & Small (S) & 40,000 & 603 \\
(incl. households) & Medium (M) & 200,000 & 1847 \\
& Large (L) & 800,000 & 5624 \\
\hline \multirow{2}{*}{ Office Building } & Small (S) & 240,000 & 400 \\
& Medium (M) & $1,200,000$ & 696 \\
& Large (L) & $3,200,000$ & 1206 \\
\hline \multirow{2}{*}{ Retail Building } & Non-food shop (NFS) & 72,000 & 310 \\
& Supermarket (SM) & 198,000 & 310 \\
\hline Electric Vehicle & Shopping centre (SC) & $12,000,000$ & 1930 \\
\hline Charging Station & Individual BEV & 3000 & 48 \\
& Residential garage & 60,000 & 144 \\
\hline
\end{tabular}

The load profile of household customers is generalised by a standard load profile H0. Typical energy intensive appliances are so-called white goods, including continuous and periodic appliances [42]. Additionally, households might be conditioned by electric radiators, infrared heating panels or split air conditioners for cooling. Electric boilers might be deployed for hot water supply. Heat pumps are frequently deployed in SFHs, offering significant flexibility potential.

The general energy demand in residential building blocks that potentially offers flexibility includes mainly ventilation and (outdoor) lighting. The data used for this analysis are derived from real data of a pilot project.

Combining the aforementioned segments results in the target segment of residential building blocks, including households.

Office buildings generally have a higher consumption due to their typical building size. The potentially flexible loads include ventilation, cooling and optionally hot water 
boilers and a heat pump-driven heating system. The data used are also derived from real data of a pilot project.

Retail buildings are a diverse segment. A main differentiation can be drawn between food retail and non-food retail. Whereas non-food retail has the major flexibility potential in ventilation and air conditioning, food retail has relevant cooling capacities such as freezers or fridges. The generalised standard load profile G4 is applied in this analysis.

Finally, BEVs constitute a relevant future source of flexibility. Depending on the reallife scenario, this segment can also be integrated in the context of one of the aforementioned user groups. In this analysis smart charging capabilities are considered to provide flexibility as a load. In future scenarios, EV charging stations might also use the BEVs' batteries as a battery storage, implying bidirectional charging (also referred to as vehicle to grid). However, vehicle to grid is out of the scope of this analysis as there are currently only few BEV models available on the market that supports this bidirectional charging [43].

Within the customer segments presented above, the individual customers might also be highly heterogenous in terms of their specific load assets deployed. Hence, the flexibility potential is individual to the specific customer. As this work aims to present a high-level view on the widespread roll out of the DR BMs in Europe among various customer segments and user profiles, the average flexibility potential is approximated in this analysis. Hence, the share of shiftable loads is considered $20 \%$ in all segments and the additional share of shedable loads is $10 \%$. Except for the BEV charging station, here $100 \%$ shiftable and $0 \%$ shedable loads are considered, as BEVs may be charged fully flexibly.

\section{Results}

\subsection{Aggregator BM}

The detailed results of the multi-level contribution margin calculation for the Aggregator BM are shown in Tables 6 and 7 for the Austrian market and in Table 8 for the UK market. For the Austrian market, scenarios have been calculated for all target segments and all building sizes. As a comparison, for the UK market the largest size of each segment has been calculated. For the household segment, a portfolio size of 10,000 customers has been considered, whereas for the most other segments the portfolio size is 500 . The customer remuneration that has been applied in these scenarios is 50\%, which means that the profit of the DR business is shared evenly between aggregator and customer. As mentioned above, the probability of the aggregator succeeding in the auctions is estimated at $80 \%$ for the capacity auction and 50\% for the energy auction.

Table 6. Results for the Aggregator BM in the Austrian market (I).

\begin{tabular}{|c|c|c|c|c|c|c|c|c|c|c|c|}
\hline \multirow{2}{*}{ Segment } & \multirow{2}{*}{$\begin{array}{l}\text { Building Type } \\
\text { Building Size }\end{array}$} & \multicolumn{3}{|c|}{ Household } & \multicolumn{3}{|c|}{ Res-excl } & \multicolumn{3}{|c|}{ Res-incl } & \multirow[t]{2}{*}{ Unit } \\
\hline & & CA & FA & SFH & S & $\mathbf{M}$ & $\mathbf{L}$ & $S$ & $\mathbf{M}$ & $\mathbf{L}$ & \\
\hline Scaling & Number of Customers & 10,000 & 10,000 & 10,000 & 500 & 500 & 500 & 500 & 500 & 500 & \\
\hline \multirow{3}{*}{$\begin{array}{l}\text { Revenue per } \\
\text { customer }\end{array}$} & Revenue Balancing Capacity & 0.50 & 0.88 & 1.25 & 2.31 & 11.55 & 46.19 & 9.81 & 49.06 & 196.24 & $€$ \\
\hline & Revenue Balancing Energy & 10.18 & 17.82 & 25.45 & 50.67 & 253.37 & 1013.50 & 203.39 & 1016.97 & 4067.87 & $€$ \\
\hline & Revenue & 10.68 & 18.69 & 26.70 & 52.98 & 264.92 & 1059.68 & 213.21 & 1066.03 & 4264.10 & $€$ \\
\hline \multirow{5}{*}{$\begin{array}{l}\text { Contribution } \\
\text { margin } 1\end{array}$} & Customer Remuneration & 5.34 & 9.35 & 13.35 & 26.49 & 132.46 & 529.84 & 106.60 & 533.01 & 2132.05 & $€$ \\
\hline & $\begin{array}{l}\text { Customer Savings Due to } \\
\text { Shedding }\end{array}$ & 5.30 & 9.27 & 13.24 & 16.70 & 83.52 & 334.08 & 64.96 & 324.81 & 1299.25 & $€$ \\
\hline & Customer Savings Total & 10.64 & 18.62 & 26.60 & 43.20 & 215.98 & 863.93 & 171.57 & 857.83 & 3431.30 & $€$ \\
\hline & Customer Savings Relative & $5 \%$ & $5 \%$ & $5 \%$ & $7 \%$ & $7 \%$ & $7 \%$ & $7 \%$ & $7 \%$ & $7 \%$ & share \\
\hline & Contribution Margin 1 & 5 & 9 & 13 & 26 & 132 & 530 & 107 & 533 & 2132 & $€$ \\
\hline \multirow{2}{*}{$\begin{array}{l}\text { Contribution } \\
\text { margin } 2\end{array}$} & Customer Fixed Costs & 80 & 94 & 108 & 282 & 372 & 584 & 603 & 1847 & 5624 & $€$ \\
\hline & Contribution Margin 2 & -75 & -85 & -95 & -256 & -240 & -54 & -496 & -1314 & -3492 & $€$ \\
\hline \multirow{3}{*}{$\begin{array}{l}\text { Operational } \\
\text { profit }\end{array}$} & Overall Contribution Margin & $-746,593$ & $-846,538$ & $-946,483$ & $-127,754$ & $-119,770$ & $-27,079$ & $-248,199$ & $-656,994$ & $-1,745,975$ & $€$ \\
\hline & Aggregator Fixed Costs & 659,400 & 659,400 & 659,400 & 510,600 & 510,600 & 510,600 & 510,600 & 510,600 & 510,600 & $€$ \\
\hline & Operational Profit & $-1,405,993$ & $-1505,938$ & $-1,605,883$ & $-638,354$ & $-630,370$ & $-537,679$ & $-758,799$ & $-1,167,594$ & $-2,256,575$ & $€$ \\
\hline
\end{tabular}


Table 7. Results for the Aggregator BM in the Austrian market (II).

\begin{tabular}{|c|c|c|c|c|c|c|c|c|c|c|c|}
\hline \multirow{2}{*}{ Segment } & \multirow{2}{*}{$\begin{array}{l}\text { Building Type } \\
\text { Building Size }\end{array}$} & \multicolumn{3}{|c|}{ Office } & \multicolumn{3}{|c|}{ Shop } & \multicolumn{3}{|c|}{ BEV } & \multirow[t]{2}{*}{ Unit } \\
\hline & & $\mathrm{S}$ & $\mathbf{M}$ & $\mathbf{L}$ & NFS & SM & SC & Single & Residen. & Business & \\
\hline Scaling & Number of Customers & 500 & 500 & 500 & 1000 & 500 & 5 & 10,000 & 500 & 500 & \\
\hline \multirow{3}{*}{$\begin{array}{l}\text { Revenue Per } \\
\text { Customer }\end{array}$} & Revenue Balancing Capacity & 59.51 & 297.56 & 793.51 & 17.86 & 49.11 & 2976.30 & 1.56 & 31.29 & 78.23 & $€$ \\
\hline & Revenue Balancing Energy & 1224.89 & 6124.43 & $16,331.80$ & 364.68 & 1002.88 & 6078.068 & 28.11 & 562.19 & 1405.66 & $€$ \\
\hline & Revenue & 1284.40 & 6421.99 & $17,125.31$ & 382.54 & 1051.99 & 6375.697 & 29.67 & 593.49 & 1483.89 & $€$ \\
\hline \multirow{5}{*}{$\begin{array}{l}\text { Contribution } \\
\text { Margin } 1\end{array}$} & Customer Remuneration & 642.20 & 3211.00 & 8562.66 & 191.27 & 526.00 & 3187.849 & 14.84 & 296.74 & 741.94 & $€$ \\
\hline & $\begin{array}{l}\text { Customer Savings Due to } \\
\text { Shedding }\end{array}$ & 451.05 & 2255.27 & 6014.04 & 129.09 & 354.99 & 2151.466 & 0.00 & 0.00 & 0.00 & $€$ \\
\hline & Customer Savings Total & 1093.25 & 5466.26 & $14,576.70$ & 320.36 & 880.99 & 533.9315 & 14.84 & 296.74 & 741.94 & $€$ \\
\hline & Customer Savings Relative & $8 \%$ & $8 \%$ & $8 \%$ & $7 \%$ & $7 \%$ & $7 \%$ & $6 \%$ & $7 \%$ & $11 \%$ & share \\
\hline & Contribution Margin 1 & 642 & 3211 & 8563 & 191 & 526 & 31878 & 15 & 297 & 742 & $€$ \\
\hline \multirow{2}{*}{$\begin{array}{l}\text { Contribution } \\
\text { Margin } 2\end{array}$} & Customer Fixed Costs & 400 & 696 & 1206 & 310 & 310 & 1930 & 48 & 144 & 256 & $€$ \\
\hline & Contribution Margin 2 & 242 & 2515 & 7357 & -119 & 216 & 29948 & -33 & 153 & 486 & $€$ \\
\hline \multirow{3}{*}{$\begin{array}{l}\text { Operational } \\
\text { Profit }\end{array}$} & Overall Contribution Margin & 121,100 & $1,257,498$ & $3,678,328$ & $-118,729$ & 107,998 & 149,742 & $-331,628$ & 76,372 & 242,972 & $€$ \\
\hline & Aggregator Fixed Costs & 510,600 & 510,600 & 510,600 & 510,600 & 510,600 & 510,600 & 659,400 & 510,600 & 510,600 & $€$ \\
\hline & Operational Profit & $-389,500$ & 746,898 & $3,167,728$ & $-629,329$ & $-402,602$ & $-360,858$ & $-991,028$ & $-434,228$ & $-267,628$ & $€$ \\
\hline
\end{tabular}

Table 8. Results for the Aggregator BM in the UK market.

\begin{tabular}{|c|c|c|c|c|c|c|c|c|}
\hline \multirow{2}{*}{ Segment } & Building Type & Household & Res-excl & Res-incl & Office & Shop & BEV & Unit \\
\hline & Building Size & SFH & $\mathbf{L}$ & $\mathbf{L}$ & $\mathbf{L}$ & SC & 50 & \\
\hline Scaling & Number of Customers & 10,000 & 500 & 500 & 500 & 5 & 500 & \\
\hline \multirow{3}{*}{$\begin{array}{l}\text { Revenue Per } \\
\text { Customer }\end{array}$} & Revenue Balancing Capacity & 6.40 & 252.96 & 1021.10 & 4046.52 & $15,144.37$ & 344.25 & $£$ \\
\hline & Revenue Balancing Energy & 0.00 & 0.00 & 0.00 & 0.00 & 0.00 & 0.00 & $£$ \\
\hline & Revenue & 6.40 & 252.96 & 1021.10 & 4046.52 & $15,144.37$ & 344.25 & $E$ \\
\hline \multirow{5}{*}{$\begin{array}{l}\text { Contribution } \\
\text { Margin } 1\end{array}$} & Customer Remuneration & 3.20 & 126.48 & 510.55 & 2023.26 & 7572.19 & 172.13 & $E$ \\
\hline & $\begin{array}{l}\text { Customer Savings Due to } \\
\text { Shedding }\end{array}$ & 12.73 & 528.97 & 2057.15 & 8519.90 & $30,479.11$ & 0.00 & $£$ \\
\hline & Customer Savings Total & 15.94 & 655.44 & 2567.70 & $10,543.15$ & $38,051.29$ & 172.13 & $£$ \\
\hline & Customer Savings Relative & $3 \%$ & $3 \%$ & $3 \%$ & $4 \%$ & $4 \%$ & $2 \%$ & share \\
\hline & Contribution Margin 1 & 3 & 126 & 511 & 2023 & 7572 & 172 & $£$ \\
\hline \multirow{2}{*}{$\begin{array}{l}\text { Contribution } \\
\text { Margin } 2\end{array}$} & Customer Fixed Costs & 93 & 502 & 4837 & 1037 & 1660 & 310 & $E$ \\
\hline & Contribution Margin 2 & -90 & -376 & -4326 & 986 & 5912 & -137 & $£$ \\
\hline \multirow{2}{*}{$\begin{array}{l}\text { Operational } \\
\text { Profit }\end{array}$} & Overall Contribution Margin & $-896,794$ & $-187,881$ & $-2,163,044$ & 493.049 & 29,562 & $-68,737$ & $E$ \\
\hline & Aggregator Fixed Costs & 567,084 & 439,116 & $1,044,900$ & 439.116 & 439,116 & 439,116 & $£$ \\
\hline
\end{tabular}

Starting with the Austrian case, the results show that for households there is a large gap between the contribution margin 1 (CM1) and the customer's fixed costs. Depending on the size of the household, the costs are about 10 times higher than CM1. Thus, for households, this BM is not profitable even on the level of the individual customer. This is also true for residential building blocks, in both cases with and without the households included. Considering only the general energy demand of a residential building block (Res-excl), with an increasing size of the building, CM2 gets better (losses decrease), which is because it is assumed that a BEMS is available and therefore only one FEID needs to be installed in the whole building. However, in a big residential building block with 200 apartments (L), CM2 is still slightly negative. Considering a residential building block, including the consumption of the households (Res-incl), this trend is different as increasing building size means increasing losses. This is because increasing size means that more individual households need to be included in the DELTA platform (e.g., with one FEID for two floors of the building) which are not controlled by a BEMS and therefore this means additional installation costs but only very low additional flexibility potential, as shown for the household segment. For all the other customer segments, a positive CM2 can mostly be achieved. For shops, this is true for supermarkets (SM) and large shopping centres (SC), but 
not for non-food shops (NFS) such as clothing stores, etc., which are not energy intensive. The results also suggest that a portfolio of 500 supermarkets is still too small to cover the overhead costs of the aggregator. However, as part of a mixed portfolio (industrial and larger commercial DR), supermarkets would be profitable. This is also true for large shopping centres, which have the highest CM2 in this analysis, but the low number of five shopping centres considered here is too small to cover the overhead costs. Office buildings are also very profitable with positive CM2 values for all sizes considered. This is also mainly because of the centralised BEMS that can be used to integrate the FEID with and control the major loads of the building. Whereas 500 small office buildings $\left(3000 \mathrm{~m}^{2}\right)$ are still too few to cover the overhead costs, a portfolio of 500 medium office buildings $\left(15,000 \mathrm{~m}^{2}\right)$ already makes up a positive operational profit (OP). A promising emerging market segment is battery electric vehicles (BEVs). For residential garages (20 BEVs) and business fleets (50 BEVs) a positive CM2 can be achieved, but a number of 500 garages/fleets is still not sufficient to reach a positive OP.

Furthermore, attention needs to be paid to the relative customer savings that can be achieved by the customer by participating in the DR programme. This is a ratio of the additional revenue received by the customer and the overall energy costs under a standard energy supplier offering. For households and residential building blocks this is about $5-7 \%$ and for the other segments it is only slightly higher, with a maximum of $11 \%$ for business EV fleets. Therefore, it can be argued that the financial incentive for customers to participate in the DR programme is limited and also other factors such as taking part in the green energy transition or convincing overall service packages might motivate customers to participate.

Against the backdrop of very limited revenues, especially in the household and residential target groups, an alternative scenario shows the results in case the aggregator would be active not only in the balancing market but also in the DA wholesale market. The results are shown in Table 9 for the household and residential segments in the Austrian market. It can be argued that the revenues can be increased by up to $30 \%$ through participation in both markets, implying that the aggregator always identifies the most profitable market. This enhances the business case, but considering the high customer fixed costs in the household and residential sector, CM2 is still negative in most of these segments. In this analysis, only the large residential buildings, excluding the households (Re-excl L), achieve a positive $\mathrm{CM} 2$ due to the additional revenues from multiple market participation.

Table 9. Results for the alternative scenario with aFRR+ and DA market participation in the Aggregator BM (Austrian market).

\begin{tabular}{|c|c|c|c|c|c|c|c|c|c|c|c|}
\hline \multirow{2}{*}{ Segment } & \multirow{2}{*}{$\begin{array}{l}\text { Building Type } \\
\text { Building Size }\end{array}$} & \multicolumn{3}{|c|}{ Household } & \multicolumn{3}{|c|}{ Res-excl } & \multicolumn{3}{|c|}{ Res-incl } & \multirow[t]{2}{*}{ Unit } \\
\hline & & CA & FA & SFH & S & $\mathbf{M}$ & $\mathbf{L}$ & $S$ & $\mathbf{M}$ & $\mathbf{L}$ & \\
\hline Scaling & Number of Customers & 10,000 & 10,000 & 10,000 & 500 & 500 & 500 & 500 & 500 & 500 & \\
\hline \multirow{3}{*}{$\begin{array}{l}\text { Revenue per } \\
\text { customer }\end{array}$} & aFRR+ Revenue & 10.34 & 18.09 & 25.84 & 45.08 & 225.39 & 901.57 & 178.08 & 890.41 & 3561.63 & $€$ \\
\hline & DA Revenue & 3.63 & 6.35 & 9.08 & 16.09 & 80.45 & 321.78 & 70.55 & 352.74 & 1410.96 & $€$ \\
\hline & Revenue & 13.97 & 24.44 & 34.91 & 61.17 & 305.84 & 1223.35 & 248.63 & 124,315 & 4972.59 & $€$ \\
\hline \multirow{5}{*}{$\begin{array}{l}\text { Contribution } \\
\text { margin } 1\end{array}$} & Customer Remuneration & 6.98 & 12.22 & 17.46 & 30.58 & 152.92 & 611.67 & 124.31 & 621.57 & 2486.29 & $€$ \\
\hline & $\begin{array}{l}\text { Customer Savings Due to } \\
\text { Shedding }\end{array}$ & 5.30 & 9.27 & 13.24 & 16.70 & 83.52 & 334.08 & 64.96 & 324.81 & 1299.25 & $€$ \\
\hline & Customer Savings Total & 12.28 & 21.49 & 30.70 & 47.29 & 236.44 & 945.76 & 189.28 & 946.39 & 3785.54 & $€$ \\
\hline & Customer Savings Relative & $6 \%$ & $6 \%$ & $6 \%$ & $8 \%$ & $8 \%$ & $8 \%$ & $8 \%$ & $8 \%$ & $8 \%$ & share \\
\hline & Contribution Margin 1 & 7 & 12 & 17 & 31 & 153 & 612 & 124 & 622 & 2486 & $€$ \\
\hline \multirow{2}{*}{$\begin{array}{l}\text { Contribution } \\
\text { margin } 2\end{array}$} & Customer Fixed Costs & 80 & 94 & 108 & 282 & 372 & 584 & 603 & 1847 & 5624 & $€$ \\
\hline & Contribution Margin 2 & -73 & -82 & -91 & -251 & -219 & 28 & -479 & -1225 & -3138 & $€$ \\
\hline \multirow{3}{*}{$\begin{array}{l}\text { Operational } \\
\text { profit }\end{array}$} & Overall Contribution Margin & $-730,171$ & $-817,800$ & $-905,428$ & $-125,708$ & $-109,541$ & 13,837 & $-239,343$ & $-612,713$ & $-1,568,853$ & $€$ \\
\hline & Aggregator Fixed Costs & 659,400 & 659,400 & 659,400 & 510,600 & 510,600 & 510,600 & 510,600 & 510,600 & 510,600 & $€$ \\
\hline & Operational Profit & $-1,389,571$ & $-1,477,200$ & $-1,564,828$ & $-636,308$ & $-620,141$ & $-496,763$ & $-749,943$ & $-1,123,313$ & $-2,079,453$ & $€$ \\
\hline
\end{tabular}

Comparing the results from the Austrian market with those from the UK, the key messages are similar. Households and residential buildings do not reach a positive CM2, but offices and shops do. Only large offices achieve a positive OP. However, BEVs do not 
reach a positive CM2. This is because the revenues are in general way lower than in the Austrian case, because - as mentioned above-participants on the FFR market typically only tender for the capacity price and not for the energy price. The relative customer savings are small, with only about $2-4 \%$. This is firstly also because of the low revenues from the FFR market and secondly because of the supplier prices in the standard offerings, which seem to be higher in the UK than in Austria.

\subsection{FLESCO BM}

The detailed results for the FLESCO BM are shown in Tables 10 and 11 for the Austrian market and in Table 12 for the UK market. For the Austrian market, scenarios have been calculated for all target segments and all building sizes. Again, for the UK market only the largest size of each segment has been calculated. Portfolio sizes are the same as in the Aggregator BM. The customer remuneration is again $50 \%$.

Table 10. Results for the FLESCO BM in the Austrian market (I).

\begin{tabular}{|c|c|c|c|c|c|c|c|c|c|c|c|}
\hline \multirow{2}{*}{ Segment } & \multirow{2}{*}{$\begin{array}{l}\text { Building Type } \\
\text { Building Size }\end{array}$} & \multicolumn{3}{|c|}{ Household } & \multicolumn{3}{|c|}{ Res-excl } & \multicolumn{3}{|c|}{ Res-incl } & \multirow[t]{2}{*}{ Unit } \\
\hline & & CA & FA & SFH & $\mathbf{S}$ & $\mathbf{M}$ & $\mathbf{L}$ & $\mathrm{S}$ & $\mathbf{M}$ & $\mathbf{L}$ & \\
\hline Scaling & Number of Customers & 10,000 & 10,000 & 10,000 & 500 & 500 & 500 & 500 & 500 & 500 & \\
\hline \multirow{3}{*}{$\begin{array}{l}\text { Revenue Per } \\
\text { Customer }\end{array}$} & Energy Costs Optimised & 96.07 & 165.86 & 235.66 & 429.97 & 2106.87 & 8409.48 & 1720.13 & 8576.64 & $34,288.56$ & $€$ \\
\hline & Energy Costs Bau & 216.68 & 364.88 & 513.08 & 615.00 & 3015.00 & $12,015.00$ & 2415.00 & $12,015.00$ & $48,015.00$ & $€$ \\
\hline & Revenue & 120.61 & 199.02 & 277.42 & 185.03 & 908.13 & 3605.52 & 694.87 & 3438.36 & $13,726.44$ & $€$ \\
\hline \multirow{3}{*}{$\begin{array}{l}\text { Contribution } \\
\text { Margin } 1\end{array}$} & Customer Remuneration & 60.31 & 99.51 & 138.71 & 92.51 & 454.07 & 1802.76 & 347.44 & 1719.18 & 6863.22 & $€$ \\
\hline & Customer Savings Relative & $28 \%$ & $27 \%$ & $27 \%$ & $15 \%$ & $15 \%$ & $15 \%$ & $14 \%$ & $14 \%$ & $14 \%$ & share \\
\hline & Contribution Margin 1 & 60 & 100 & 139 & 93 & 454 & 1803 & 347 & 1719 & 6863 & $€$ \\
\hline \multirow{2}{*}{$\begin{array}{l}\text { Contribution } \\
\text { Margin } 2\end{array}$} & Customer Fixed Costs & 80 & 94 & 108 & 282 & 372 & 584 & 603 & 1847 & 5624 & $€$ \\
\hline & Contribution Margin 2 & -20 & 6 & 31 & -189 & 82 & 1219 & -256 & -128 & 1239 & $€$ \\
\hline \multirow{3}{*}{$\begin{array}{c}\text { Operational } \\
\text { Profit }\end{array}$} & Overall Contribution Margin & $-196,927$ & 55.078 & 307,083 & $-94,743$ & 41,033 & 609,381 & $-127,782$ & -63.910 & 619,609 & $€$ \\
\hline & FLESCO Fixed Costs & 659,400 & 659.400 & 659,400 & 510,600 & 510,600 & 510,600 & 510,600 & 510,600 & 510,600 & $€$ \\
\hline & Operational Profit & $-856,327$ & -604.322 & $-352,317$ & $-605,343$ & $-469,567$ & 98,781 & $-638,382$ & $-574,510$ & 109,009 & $€$ \\
\hline
\end{tabular}

Table 11. Results for the FLESCO BM in the Austrian market (II).

\begin{tabular}{|c|c|c|c|c|c|c|c|c|c|c|c|}
\hline \multirow{2}{*}{ Segment } & \multirow{2}{*}{$\begin{array}{l}\text { Building Type } \\
\text { Building Size }\end{array}$} & \multicolumn{3}{|c|}{ Office } & \multicolumn{3}{|c|}{ Shop } & \multicolumn{3}{|c|}{ BEV } & \multirow[t]{2}{*}{ Unit } \\
\hline & & $S$ & $\mathbf{M}$ & $\mathbf{L}$ & NFS & SM & SC & Single & Residen. & Business & \\
\hline Scaling & Number of Customers & 500 & 500 & 500 & 500 & 500 & 5 & 10,000 & 500 & 500 & \\
\hline \multirow{3}{*}{$\begin{array}{l}\text { Revenue Per } \\
\text { Customer }\end{array}$} & Energy Costs Optimised & $10,323.41$ & $51,593.04$ & $137,571.45$ & 3085.65 & 8475.04 & $513,281.09$ & 90.78 & 1613.02 & 4024.04 & $€$ \\
\hline & Energy Costs Bau & $14,415.00$ & $72,015.00$ & $192,015.00$ & 4335.00 & 11895.00 & $720,015.00$ & 234.86 & 4334.66 & 6567.00 & $€$ \\
\hline & Revenue & 4091.59 & $20,421.96$ & $54,443.55$ & 1249.35 & 3419.96 & $206,733.91$ & 144.08 & 2721.64 & 2542.96 & $€$ \\
\hline \multirow{3}{*}{$\begin{array}{l}\text { Contribution } \\
\text { Margin } 1\end{array}$} & Customer Remuneration & 2045.80 & $10,210.98$ & $27,221.78$ & 624.67 & 1709,98 & $103,366.95$ & 72.04 & 1360.82 & 1271.48 & $€$ \\
\hline & Customer Savings Relative & $14 \%$ & $14 \%$ & $14 \%$ & $14 \%$ & $14 \%$ & $14 \%$ & $31 \%$ & $31 \%$ & $19 \%$ & share \\
\hline & Contribution Margin 1 & 2046 & 10,211 & 27,222 & 625 & 1710 & 103,367 & 72 & 1361 & 1271 & $€$ \\
\hline \multirow{2}{*}{$\begin{array}{l}\text { Contribution } \\
\text { Margin } 2\end{array}$} & Customer Fixed Costs & 400 & 696 & 1206 & 310 & 310 & 1930 & 48 & 144 & 256 & $€$ \\
\hline & Contribution Margin 2 & 1646 & 9515 & 260,16 & 315 & 1400 & 101,437 & 24 & 1217 & 1015 & $€$ \\
\hline \multirow{3}{*}{$\begin{array}{c}\text { Operational } \\
\text { Profit }\end{array}$} & Overall Contribution Margin & 822,898 & $4,757,489$ & $13,007,888$ & 157,337 & 699,990 & 507,185 & 240,413 & 608,411 & 507,741 & $€$ \\
\hline & FLESCO Fixed Costs & 510,600 & 510,600 & 510,600 & 510,600 & 510,600 & 510,600 & 659,400 & 510,600 & 510,600 & $€$ \\
\hline & Operational Profit & 312,298 & $4,246,889$ & $12,497,288$ & $-353,263$ & 189390 & -3415 & $-418,987$ & 97,811 & -2859 & $€$ \\
\hline
\end{tabular}


Table 12. Results for the FLESCO BM in the UK market.

\begin{tabular}{|c|c|c|c|c|c|c|c|c|}
\hline \multirow{2}{*}{ Segment } & Building Type & Household & Res-excl & Res-incl & Office & Shop & BEV & Unit \\
\hline & Building Size & SFH & $\mathbf{L}$ & $\mathbf{L}$ & $\mathbf{L}$ & SC & Business & \\
\hline Scaling & Number of Customers & 10,000 & 500 & 500 & 500 & 5 & 500 & \\
\hline \multirow{3}{*}{$\begin{array}{l}\text { Revenue Per } \\
\text { Customer }\end{array}$} & Energy Costs Optimised & 311.93 & $11,265.89$ & $46,632.31$ & $183,726.70$ & $694,647.09$ & 5400.09 & $£$ \\
\hline & Energy Costs Bau & 518.80 & $17,060.23$ & $68,060.23$ & $272,060.23$ & $1,020,060.23$ & 9342.23 & $£$ \\
\hline & Revenue & 206.87 & 5794.34 & $21,427.92$ & $88,333.52$ & $325,413.13$ & 3942.14 & $£$ \\
\hline \multirow{3}{*}{$\begin{array}{l}\text { Contribution } \\
\text { Margin } 1\end{array}$} & Customer Remuneration & 103.43 & 2897.17 & $10,713.96$ & $44,166.76$ & $162,706.57$ & 1971.07 & $£$ \\
\hline & Customer Savings Relative & $20 \%$ & $17 \%$ & $16 \%$ & $16 \%$ & $16 \%$ & $21 \%$ & share \\
\hline & Contribution Margin 1 & 103 & 2897 & 10,714 & 44,167 & 162,707 & 1971 & $£$ \\
\hline \multirow{2}{*}{$\begin{array}{l}\text { Contribution } \\
\text { Margin } 2\end{array}$} & Customer Fixed Costs & 93 & 502 & 4837 & 1037 & 1660 & 310 & $£$ \\
\hline & Contribution Margin 2 & 11 & 2395 & 5877 & 43,130 & 161,047 & 1661 & $£$ \\
\hline \multirow{3}{*}{ Operational Profit } & Overall Contribution Margin & 105,547 & 119,7465 & 293,8660 & 2156,4801 & 805,234 & 830,734 & $£$ \\
\hline & FLESCO Fixed Costs & 567,084 & 439,116 & 439,116 & 439,116 & 439,116 & 439,116 & $£$ \\
\hline & Operational Profit & $-461,537$ & 758,349 & 249,9544 & 2112,5685 & 366,118 & 391,618 & $£$ \\
\hline
\end{tabular}

In the Austrian example, for households the categories family apartment (FA) and single-family house (SFH) already achieve a small but positive value in CM2. However, given the small CM2, a portfolio size of 10,000 is still way too small to make a positive OP. For residential building blocks, the largest category (L), not only a positive CM2 but also a positive OP can be achieved with the given portfolio size of 500. Note that the difference in CM2 for Res-excl (EUR 1219) and Res-incl (EUR 1239) is negligible, but the costs for Res-incl are significantly higher due to the additional installations for all individual households. This means it can be expected that the revenues for the additional flexibility from the households is eaten up by the additional costs needed. For office buildings, the FLESCO model suggests very promising results with a positive OP also in the smallest category (S). The scenario with the highest OP in this analysis is achieved by large office buildings (L). Additionally, the category of shops is promising for the FLESCO model. Non-food shops (NFS) with a relatively low energy consumption already reach a positive CM2. Supermarkets (SM) show a positive OP in the given scenarios and shopping centres (SC) have the highest individual CM2. This is similar for BEVs. Individual BEVs (Single) already achieve a positive CM2, but a portfolio of 10,000 is still too small for a FLESCO.

The relative customer savings are significant in the FLESCO model with a range of about 15\% (Res-excl and Res-incl) up to 31\% (BEVs). In the UK market, the results are similarly promising with positive OPs in all categories except from individual households.

\section{Discussion and Conclusions}

This paper has conducted an economic assessment of two DR BMs enabled by the DELTA solution, with a focus on typical currently uncontrolled load assets. In order to discuss the research questions raised above, this section firstly discusses the calculation results. Then, an overall discussion and outlook on the future of DR BMs for small- and medium-sized prosumers is given, and it is discussed which role technological advances, such as those developed in DELTA, will play in the further development of this market.

\subsection{Discussion on Calculation Results}

It can be argued that the relation between revenues and costs is unfavourable in both DR BMs. This especially true for the residential sector. Here, in the most scenarios, the customer's fixed costs for installation, contracting, customer support, etc., already outweigh the contribution margin (CM1) achieved by far, although a fair sharing of revenues (50/50) between aggregator/FLESCO and customer has been assumed. If these customer fixed costs can be covered (meaning a positive CM2), as it is the case in many scenarios for office buildings, shops and BEV fleets, it is a matter of the aggregator's/FLESCO's portfolio size that makes a positive operational profit or not. 
The customer savings consist of savings due to load shifting and savings due to load shedding. It is worth noting that shedding has a high impact on the overall cost savings for the end-users, as it means that less energy is consumed, whereas in load shifting the same amount of energy is consumed. Although the scenarios have considered load shedding to a lower extent than load shifting, in the Aggregator BM, the savings due to shedding play an important role for the customers' profit. This is because a $\mathrm{kWh}$ purchased from the energy supplier has a higher price than a kWh flexibility shifted for aFRR or FFR. This means in a scenario with only load shifting and not load shedding, the benefit for the end-users would decrease significantly. This is also true for the FLESCO BM, but the calculation model does not explicitly differentiate between the savings due to shifting vs. the savings due to shedding.

Analysing more in detail the viability of the Aggregator BM, the results show that the residential sector is not attractive for this BM and only medium and large tertiary buildings are promising. The major part of the revenues in the case of the Austrian aFRR+ market comes from the balancing energy provided, whereas the revenue for balancing capacity is negligible. In the UK FFR it is the other way round, with the balancing capacity being the focus of tenderers and the balancing energy is often not tendered at all. Considering a fair customer remuneration with $50 \%$ of the revenues, CM2 remains very small, especially for household customers. In the Austrian case, the customer fixed costs for households are nearly 10 times higher than the CM1. For whole residential building including the households this ratio is still about 1.5-4. In the UK this is even more drastic with a ratio of about 9 for residential building blocks and 30 for individual households. This means that only office buildings, shops and BEV fleets are potentially interesting as a target segment in this BM, as only they achieve a positive CM2. However, reaching a positive OP still depends on the size of the aggregator's portfolio. In Austria, a portfolio of 500 medium or large office buildings seems feasible, whereas 500 shops and 5 shopping centres are still not enough to cover the aggregator's overhead costs. This is similar in the UK market. Considering multiple market participation, the alternative scenario suggests that the revenues could increase up to $30 \%$, which has only a small effect on the final results considering the high customer fixed costs.

In the FLESCO BM, the results are more optimistic, but they always depend on the ToU pricing scheme applied and the flat pricing scheme used as a cost baseline. The calculated savings are considerable and exceed the customer fixed costs in many scenarios. This includes even family apartments, single family houses and large residential buildings, but of course also offices, shops and BEV fleets. However, a positive OP still seems not possible for a portfolio of 10,000 households, but for pools of 500 large residential buildings, tertiary buildings and BEV fleets.

Concluding from these results, it needs to be discussed which BM has a fair chance to be successful in a widespread implementation. The calculations show that the FLESCO $\mathrm{BM}$ leads to the most promising results. The general design of the FLESCO BM implies that the FLESCO also benefits from the cost savings due to load shedding. Especially in scenarios with a high share of load shedding this would make a huge impact on the CM. In the Aggregator BM, solely the customer benefits from the reduction of energy consumed through load shedding.

\subsection{Overall Conclusions on the Viability of the DELTA BMs}

Generally, all the BMs analysed suffer from a certain cost problem that makes a profitable business case for individual households not possible. The Aggregator BM has high technical requirements for participating on balancing markets and relatively small revenues, which makes it only appealing for larger customers that can offer larger power capacities. In contrast, the FLESCO BM has rather low technical requirements (e.g., no guarantee is needed for actually dispatching flexibility such as in explicit markets) which makes it attractive for small distributed prosumers. However, as shown in the calculations, this BM also does not enable a positive OP for individual households. 
For the scenarios where a positive CM2 has been achieved, the portfolio size is decisive. To reach the portfolio sizes as assumed in the calculation (e.g., 10,000 household customers, 500 tertiary buildings) or even larger, strong partners with access to numerous end-users are needed. This could be energy suppliers with many end users, technology manufacturers such as charging point operators, or companies with large property assets such as supermarket chains.

For all target segments, the authors conclude that there is range of preconditions that need to be met to have chance for one of the DELTA BMs to be successful. From a technical perspective, it can be argued that the costs for installing and connecting the DELTA hardware can only be kept in an acceptable range if the building is already fully "smart". This means firstly that all relevant energy consuming devices need to be ready for IoT communication and secondly that there are no additional costs for upgrading connectivity in the building. The latter means that there are already ethernet cables or wireless connectivity (Wi-Fi or GSM) available, also in remote parts of a building such as the basement where heat pumps and BEMS are often located. Another vital precondition is that all DR interventions need to be fully automatic and no manual intervention is needed. Considering the low financial incentives, it can be expected that end-users will not put any effort in reacting manually to explicit DR requests or implicit changes in the energy price. From the perspective of the service provider another precondition is the sufficiently large portfolio as mentioned above. This means that only big players can survive in this market, as for overhead costs the effect of economy of scales heavily applies.

Beyond that, there are many aspects that need to be considered by service providers to cut down transaction costs, including customer fixed costs and overhead costs. A BEMS plays an important role to achieve this cost reduction. If a BEMS is available that can control all major energy consuming devices in the building, only one FEID needs to be installed at the BEMS. In addition, connecting a FEID in the BEMS requires significantly less efforts than connecting each device individually to the FEID. From the sales perspective of the service provider, it is important to get access to the most promising customers in terms of their flexibility potential and their controllability. In this respect, service providers should follow an asset-oriented approach. This means that the service provider selects promising customers depending on their flexible assets. This could be a heat pump manufacturer contacting owners of smart-ready heat pumps in order to increase efficiency of the customer acquisition process. Another strategy for future acquisition of small- and medium-sized prosumers could be through energy communities which are already connected with each other. A FLESCO or aggregator could offer its services for prosumers of such a community and enhance the business case of the community for them. Moreover, the DR services need to be integrated in comprehensive service packages in order to be successful. This could cut down many cost elements, including customer acquisition, contracting and installation.

In both BMs the role of technology advances and big data processing is vital. On the one hand, it is a prerequisite to enable the BMs at all, which considers the FEID and the DVN as well as data-driven flexibility and price forecasting algorithms. On the other hand, it is an important tool to cut down the transaction costs through user-clustering, self-subscription and smart contracts, for instance. However, the analysis revealed that although technology can make the BMs as efficient as possible, the revenues that can be achieved are very small in most scenarios for small- and medium-sized prosumers. This means the market determines a "natural limit" for potential revenues that can be achieved whereas technology can only reduce the costs as much as possible. Concluding from the cost calculations, this gap between potential revenues and costs remains significant for most target segments, although costs are minimised by advanced IoT technology and data-driven algorithms.

\subsection{Limitations of the Analysis}

The analysis provided in this paper is subject to certain limitations in terms of its methodology. However, it's worth noting that the approach of DELTA is to address the 
hidden flexibility potential of small and medium prosumers and therefore deals with various heterogenous load types. To tackle these various assets in the target segments analysed, the flexibility potential has not been modelled in detail per load asset, but an approximation has been applied based on the typical load profiles of these users. This simplification gives a more high-level perspective of the order of magnitude regarding the expected flexibility gains from these target segments, rather than an optimisation per load asset type. Similarly, participation in multiple flexibility markets has not been analysed exhaustively in this analysis, but only based on a specific example scenario. Hence, slightly increasing revenues could be expected for the Aggregator BM in case of optimal bidding in several markets. Finally, EVs, which can be seen as promising flexibility assets of small end-users in the future, are only considered as a load in the context of smart charging as the currently dominant market-ready technology. This means that vehicle-to-grid technologies have been neglected, which might become a relevant technology on the market in the medium term, adding another layer of potential revenues to the EV business cases for DR.

\subsection{Outlook}

The results of this work suggest that for small prosumers the cost savings or revenues will not be the main driver for participating in one of the BMs analysed. For households the maximum savings account to $5-7 \%$ in the Aggregator BM and even more than $25 \%$ in the FLESCO model, but in both cases the service provider would need to keep a way higher proportion of the savings to cover all the costs which would in return reduce the profit of the customer. Therefore, drivers for this BMs could be "smart home" devices or building automation systems in general with the main value proposition of delivering comfort to the building users and DR participation can then be offered as an add-on service. Another driver could be the emerging energy communities. The main purpose of energy communities are not financial gains, but social and ecologic aspects. In energy communities, which primarily want to actively contribute to the energy transition, DR schemes could be interesting for the members.

Another relevant aspect for the replication especially of the residential BMs is the future development of energy consumption profiles. A shift in consumption patterns has been drastically demonstrated through the pandemic situation in 2020 and the consequent prevention measures taken by national governments. During this time, household energy profiles have changed significantly due to higher occupancy related to isolation or remote working. The latter trend is expected to continue, as future workplaces are less dependent on physical presence. As a result, this could permanently change residential load profiles, which needs to be taken into account for future works regarding household BMs.

Coming back to the financial aspect, the question arises if small prosumers should actively participate on energy markets that have been designed for large scale power generators. As highlighted by EU policies, energy efficiency should be the first priority especially for small end-users. In addition, this analysis revealed that large parts of the financial gains for the end-users are realised through load shedding, which actually is a form of energy efficiency, as the total amount of energy consumed is decreased. Another theoretical aspect when thinking about high market penetration of flexible demand side resources is competition. If the amount of flexibility offered increases, the market prices also adapt to this additional competition and might decrease. Future market development will show if the flexibility needs in the system will grow faster than the flexible resource available for providing DR.

Finally, it can be argued that market prices on the analysed markets need to increase to enable profitable BMs for DR. It is not clear if such a jump in prices is realistic in the medium term on the existing markets. However, flexible distributed loads could play an important role in the future for local congestion management. Currently, there are no markets in place where local flexibility is procured in a market-based way, but the unique location of distributed flexible resources makes them potential solutions for these local grid problems. 
Author Contributions: Conceptualization, G.P., C.A., K.L.; methodology, G.P.; software, G.P.; validation, G.P., C.A.; formal analysis, G.P.; investigation, G.P.; data curation, G.P.; writing-original draft preparation, G.P.; writing-review and editing, C.A.; visualization, G.P.; supervision, C.A.; project administration, G.P., C.A.; funding acquisition, C.A., K.L. All authors have read and agreed to the published version of the manuscript.

Funding: This research, including the APC, was funded by the European Union's Horizon 2020 research and innovation programme under grant agreement No. 773960.

Acknowledgments: The authors would like to thank all partners involved in the DELTA project, especially those who have contributed to the work package on business model development.

Conflicts of Interest: The authors declare no conflict of interest. The funders had no role in the design of the study; in the collection, analyses, or interpretation of data; in the writing of the manuscript, or in the decision to publish the results.

\section{Appendix A. Market Data}

The average balancing capacity and balancing energy prices per time slice (there are 6 time slices per day) and season are shown in Table A1 for the Austrian aFRR+ market.

Table A1. aFRR+ market prices in Austria 2020 [37].

\begin{tabular}{ccccccccc}
\hline & \multicolumn{3}{c}{ Capacity Price $(\boldsymbol{€} / \mathbf{m W h})$} & \multicolumn{3}{c}{ Energy Price $(\boldsymbol{€} / \mathbf{m W h})$} \\
\hline Time Slice & Spring & Summer & Fall & Winter & Spring & Summer & Fall & Winter \\
\hline 1 & 0.01 & 0.02 & 0.68 & 0.34 & 44.27 & 52.96 & 66.35 & 69.22 \\
2 & 0.15 & 0.39 & 1.87 & 0.93 & 52.73 & 92.86 & 81.99 & 75.43 \\
3 & 0.28 & 1.04 & 4.39 & 2.64 & 62.51 & 72.72 & 88.77 & 92.82 \\
4 & 0.03 & 0.26 & 1.22 & 1.43 & 54.17 & 52.73 & 86.59 & 80.03 \\
5 & 0.85 & 1.47 & 5.41 & 3.50 & 70.60 & 69.70 & 88.74 & 85.81 \\
6 & 0.33 & 1.75 & 2.45 & 0.68 & 65.83 & 83.14 & 94.95 & 76.80 \\
\hline
\end{tabular}

For the UK market, Table A2 shows the median capacity prices in each season on the secondary FFR market.

Table A2. Secondary FFR market prices in UK 2020 [38].

\begin{tabular}{cccc}
\hline \multicolumn{4}{c}{ Capacity Price $(£ /$ MWh $)$} \\
\\
\hline Spring & Summer & Fall & Winter \\
\hline 7.09 & 6.24 & 8.70 & 9.50 \\
\hline
\end{tabular}

The probability of having a flexibility request in a given point in time ( $30 \mathrm{~min}$ interval) is shown in Table A3. The data are derived from the Austrian aFRR+ market, as averages per time slice and season. Due to a lack of this data for the UK market, the probabilities from Austria are also assumed for the UK FFR market. Note, that this simplification only affects the customer savings but not the contribution margins. This is because in the UK FFR market only the capacity price is tendered.

Table A3. Probability of flexibility request in the aFRR+ market in Austria 2020 [44].

\begin{tabular}{ccccc}
\hline Time Slice & Spring & Summer & Fall & Winter \\
\hline 1 & $76 \%$ & $93 \%$ & $91 \%$ & $90 \%$ \\
2 & $68 \%$ & $92 \%$ & $93 \%$ & $90 \%$ \\
3 & $71 \%$ & $89 \%$ & $89 \%$ & $77 \%$ \\
4 & $73 \%$ & $90 \%$ & $94 \%$ & $81 \%$ \\
5 & $81 \%$ & $93 \%$ & $91 \%$ & $77 \%$ \\
6 & $71 \%$ & $90 \%$ & $92 \%$ & $82 \%$ \\
\hline
\end{tabular}

To estimate the BaU energy costs of a prosumer, typical offerings from incumbent energy suppliers in the UK and Austria have been selected. In Austria the incumbent 
energy supplier of the city of Vienna "Wien Energie" has been chosen (Table A4). It does only include the offering of the energy supplier, without any grid tariffs and taxes.

Table A4. Details of the standard offering of Wien Energie.

\begin{tabular}{ccccc}
\hline & \multicolumn{2}{c}{ Household “Optima” } & \multicolumn{2}{c}{ Business “Klassik” } \\
\hline Electricity Unit Price & 0.0988 & $€ / \mathrm{kWh}$ & 0.06 & $€ / \mathrm{kWh}$ \\
Electricity Standing Charge & 19.0800 & $€ /$ year & 15 & $€ /$ year \\
\hline
\end{tabular}

The flat energy pricing schemes used as a reference in the UK are from "British Gas". However, the prices offered in the UK always include not only the energy price of the supplier, but also grid tariffs and taxes. As shown in Figure A1, only about $50 \%$ are the costs for the energy supplier (wholesale costs and supplier operating costs). Thus, the prices used for this calculation are reduced by $50 \%$. The original and the adapted prices used for the calculation are shown in Table A5.

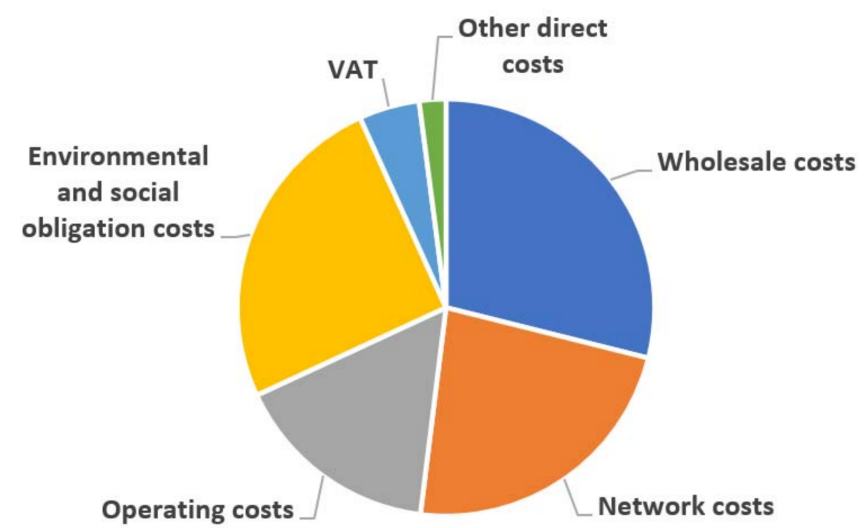

Figure A1. Breakdown of a UK electricity bill, based on [45].

Table A5. Details of the standard offering of British Gas.

\begin{tabular}{ccccc}
\hline & $\begin{array}{c}\text { Household “Standard } \\
\text { Variable” }\end{array}$ & \multicolumn{2}{c}{$\begin{array}{c}\text { Business “British Gas } \\
\text { Light” }\end{array}$} \\
\hline Electricity Unit Price & 0.19 & $£ / \mathrm{kWh}$ & 0.17 & $£ / \mathrm{kWh}$ \\
Electricity Standing Charge & 87.6 & $£ /$ year & 120.45 & $£ /$ year \\
\hline Electricity Unit Price Adapted (50\%) & 0.095 & $£ / \mathrm{kWh}$ & 0.085 & $£ / \mathrm{kWh}$ \\
Electricity Standing Charge Adapted (50\%) & 43.8 & $£ /$ year & 60.225 & $£ /$ year \\
\hline
\end{tabular}

For the supplier surcharge that is added to the DA prices in the FLESCO model, the offering of the Austrian supplier Spotty [46] has been used as an example in this analysis (Table A6).

Table A6. Supplier fees of Spotty AT [46].

\begin{tabular}{ccccc}
\hline Customer Size & $<\mathbf{8 0 0 0}$ & $\mathbf{8 0 0 0 - 4 0 , 0 0 0}$ & $>\mathbf{4 0 , 0 0 0}$ & $\mathbf{k W h} / \mathbf{a}$ \\
\hline Surcharge on spot market price & 0.0048 & 0.0019 & 0.0014 & $€ / \mathrm{kWh}$ \\
Basic supplier fee & 3.0 & 4.8 & 6.0 & $€ / \mathrm{month}$ \\
\hline
\end{tabular}

The ToU pricing schemes are derived from the national DA market prices and are shown in Figures A2 and A3 (without supplier surcharge). 


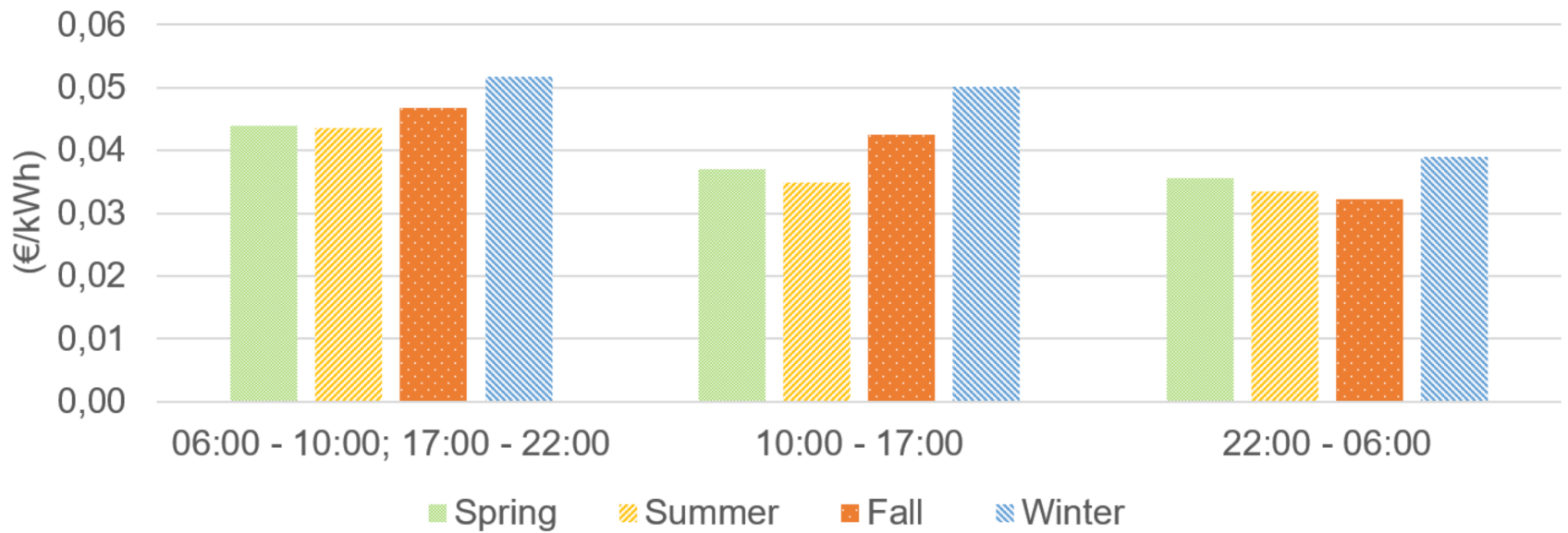

Figure A2. ToU prices without supplier fees-Austria.

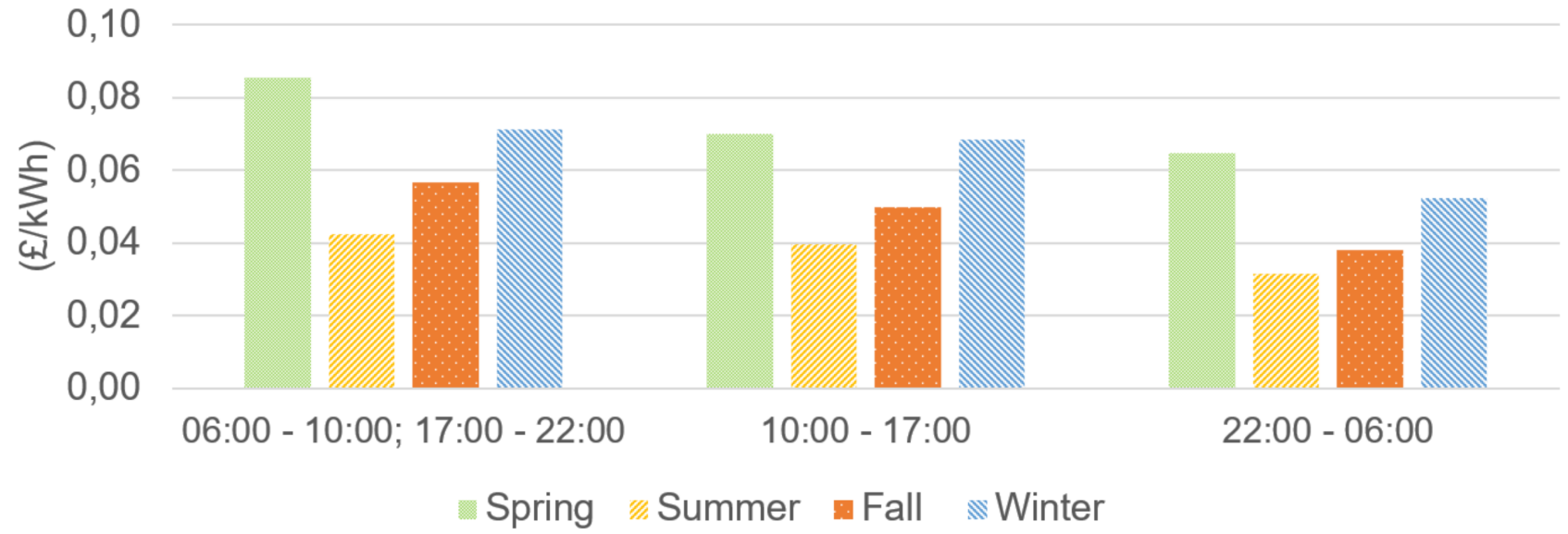

Figure A3. ToU prices without supplier fees-UK.

\section{Appendix B. Target Segments and Cost Data}

In order to make plausible assumptions on the various cost elements, a bottom-up approach has been followed. For each element, estimates have been drawn in a stakeholder dialogue, mainly in cooperation with following partners of the DELTA project:

- Pilot site managers, who have conducted the installation works at the DELTA pilot site premises.

- Technology developers, who have developed key technical components of the DELTA solution (such as the FEID).

- An aggregator, who is experienced with the operational work in existing DR schemes, including customer targeting and cost calculation of individual projects.

From all the assumptions, the final costs are derived as annual costs. The BMs are calculated for a time horizon of 5 years, which means that after 5 years the costs for equipment, installation etc. should be amortised. The general assumptions for labour costs and the price of the FEID are shown in Table A7.

Table A7. General cost assumptions for labour costs and FEID price.

\begin{tabular}{cccc}
\hline Assumption & Value & Source \\
\hline Administrative Staff Costs & 50 & $€ / \mathrm{h}$ & derived from [47,48] \\
Electrician Staff Costs & 70 & $€ / \mathrm{h}$ & derived from [48,49] \\
FEID Price & 100 & per FEID & extrapolated from FEID prototyping costs \\
\hline
\end{tabular}




\section{Appendix B.1. Households}

For individual household customers, the standard load profile H0 from [50] has been applied. Figure A4 shows this profile as an example on a typical day in shoulder season.

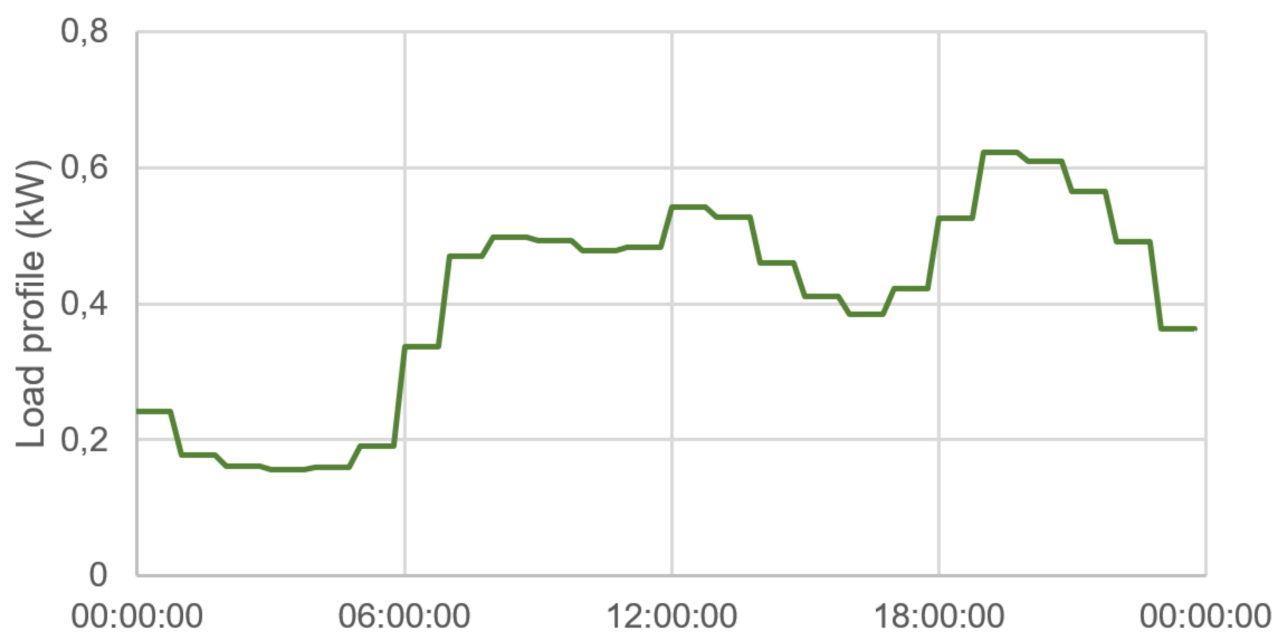

Figure A4. Load profile of household customer (family apartment) on a day in shoulder season (9 April).

This standard load profile has been adapted for three sizes of household customers: A couple apartment, a family apartment and a single-family house. For each of these exemplary customers, the customer fixed costs have been estimated based on the bottomup approach starting from specific cost items Table A8.

Table A8. Annual cost data for customer fixed costs (household).

\begin{tabular}{|c|c|c|c|c|c|}
\hline & \multirow{2}{*}{ Consumer Type } & \multicolumn{3}{|c|}{ Household } & \multirow[b]{3}{*}{ Quantity Required per 5-Year Period * } \\
\hline & & CA & FA & SFH & \\
\hline & $\begin{array}{c}\text { Annual Electricity } \\
\text { Consumption (kWh) }\end{array}$ & 2000 & 3500 & 5000 & \\
\hline Category & Cost item & $(€)$ & $(€)$ & $(€)$ & \multirow[b]{2}{*}{$\begin{array}{c}1 \text { FEID } \\
\text { no other hardware expected } \\
\text { not for household customers } \\
\text { E: } 2 / 3 / 4 \mathrm{~h}\end{array}$} \\
\hline Investment & $\begin{array}{c}\text { FEID } \\
\text { Other Hardware } \\
\text { Establish communication } \\
\text { Installation }\end{array}$ & $\begin{array}{l}20 \\
- \\
- \\
28\end{array}$ & $\begin{array}{l}20 \\
- \\
- \\
42\end{array}$ & $\begin{array}{l}20 \\
- \\
- \\
56\end{array}$ & \\
\hline Contracting & $\begin{array}{l}\text { Commercial feasibility } \\
\text { Technical feasibility } \\
\text { Contract conclusion }\end{array}$ & $\begin{array}{c}20 \\
- \\
5\end{array}$ & $\begin{array}{c}20 \\
- \\
5\end{array}$ & $\begin{array}{c}20 \\
\overline{5}\end{array}$ & $\begin{array}{c}\text { A: } 2 \mathrm{~h} \text {; no on-site visit } \\
\text { not for household customers } \\
\text { A: } 0.5 \mathrm{~h}\end{array}$ \\
\hline \multirow[t]{2}{*}{ Operation/Maintenance } & $\begin{array}{l}\text { on-site trouble shooting } \\
\text { remote maintenance }\end{array}$ & $\begin{array}{l}0 \\
7\end{array}$ & $\begin{array}{l}0 \\
7\end{array}$ & $\begin{array}{l}0 \\
7\end{array}$ & $\begin{array}{l}\text { not for household customers } \\
\text { E: } 0,5 \mathrm{~h}\end{array}$ \\
\hline & $\begin{array}{l}\text { TOTAL customer fixed } \\
\text { costs }\end{array}$ & 80 & 94 & 108 & ${ }^{*} \mathrm{~A}=$ Administrative staff; $\mathrm{E}=$ Electrician \\
\hline
\end{tabular}

Quantity Required per 5-Year Period *

The annual costs for the FEID result from the number of FEIDs needed for the specific customer and the FEID price given above (Note, that all the quantities refer to a life cycle of 5 years, but the costs are annual costs). No other hardware (sensors etc.) are planned, the FEID contains all the necessary functionalities. However, a smart meter is considered a prerequisite and has to be available at the customer's site. Similarly, it is also a prerequisite, that communication is ensured in the building either through ethernet lines or wireless internet connection (GSM, Wi-Fi). This has to be the case in all areas of the building where switchable devices are located, so also in the basement where heat pumps or car charging stations might be located, for instance. The contracting costs include a feasibility assessment, in which it needs to be checked in advance, if it makes sense from a commercial and technical perspective to include the customer in the DR programme. Important factors are the flexibility potential of the devices and the technical interoperability. Contract 
conclusion includes the signing and verifying of the official paperwork to take a new customer under contract. Finally, during operation there might be some online or on-site troubleshooting to solve technical problems.

\section{Appendix B.2. Residential Building Blocks (Excl. Households)}

This target segment considers residential building blocks, but it is assumed that only the general energy demand of the building (lighting in staircase, HVAC, etc.) can be controlled by the FEID. This is because such loads can be controlled through a central BEMS and therefore only one FEID needs to be installed and one contract with the building owner needs to be made.

The load profile for this kind of energy demand is derived from an Austrian research project, see [51]. Figure A5 shows this profile as an example on a typical day in shoulder season. The cost data for this customer segment are given in Table A9.

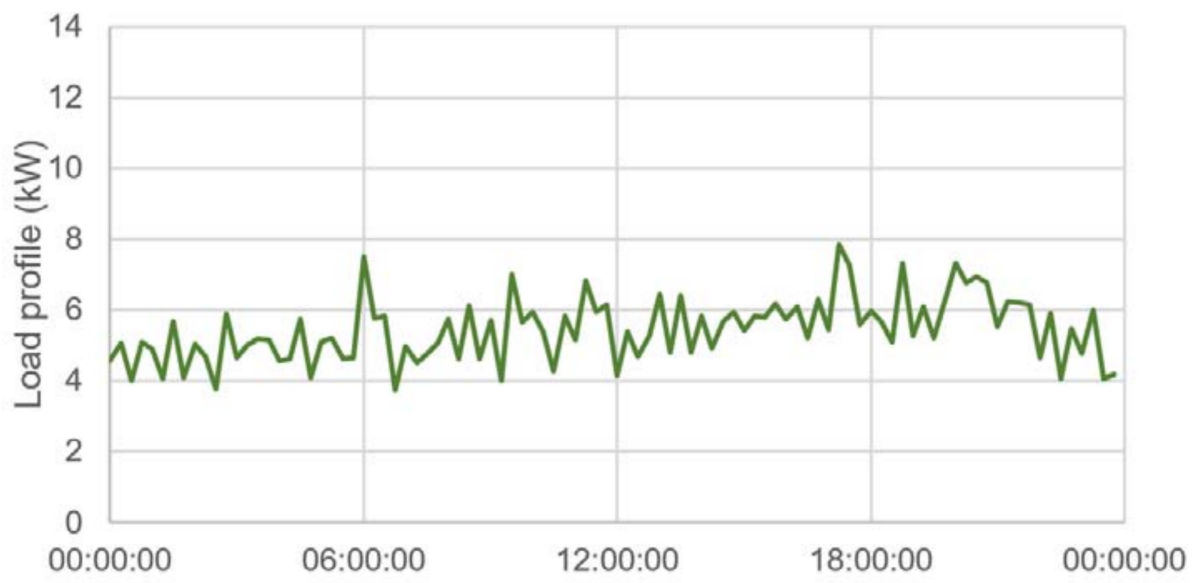

Figure A5. Load profile of the general energy demand (excl. households) of a residential building block (medium) on a day in shoulder season (9 April).

Table A9. Annual cost data for customer fixed costs (Residential building blocks excl. households).

\begin{tabular}{|c|c|c|c|c|c|}
\hline & \multirow{2}{*}{ Consumer Type } & \multicolumn{3}{|c|}{$\begin{array}{l}\text { Residential Building } \\
\text { (Excl. Households) }\end{array}$} & \multirow{4}{*}{ Quantity Required per 5-Year Period * } \\
\hline & & $\mathbf{S}$ & $\mathbf{M}$ & $\mathbf{L}$ & \\
\hline & $\begin{array}{l}\text { Annual Electricity } \\
\text { Consumption (kWh) }\end{array}$ & 10,000 & 50,000 & 200,000 & \\
\hline Category & Cost item & $(€)$ & $(€)$ & $(€)$ & \\
\hline Investment & $\begin{array}{c}\text { FEID } \\
\text { Other Hardware } \\
\text { Establish communication } \\
\text { Installation }\end{array}$ & $\begin{array}{l}20 \\
- \\
- \\
56\end{array}$ & $\begin{array}{l}20 \\
- \\
- \\
56\end{array}$ & $\begin{array}{c}20 \\
- \\
- \\
112\end{array}$ & $\begin{array}{c}1 \text { FEID } \\
\text { BEMS available } \\
\text { BEMS available } \\
\text { E: } 4 / 4 / 8 \mathrm{~h}\end{array}$ \\
\hline Contracting & $\begin{array}{l}\text { Commercial feasibility } \\
\text { Technical feasibility } \\
\text { Contract conclusion }\end{array}$ & $\begin{array}{l}50 \\
70 \\
30\end{array}$ & $\begin{array}{l}70 \\
98 \\
30\end{array}$ & $\begin{array}{c}100 \\
140 \\
30\end{array}$ & $\begin{array}{l}\text { A: } 5 / 7 / 10 \mathrm{~h} \\
\text { E: } 5 / 7 / 10 \mathrm{~h} \\
\text { A: } 3 / 3 / 3 \mathrm{~h}\end{array}$ \\
\hline \multirow[t]{4}{*}{ Operation/Maintenance } & $\begin{array}{l}\text { on-site trouble shooting } \\
\text { remote maintenance }\end{array}$ & $\begin{array}{l}28 \\
28\end{array}$ & $\begin{array}{l}56 \\
42\end{array}$ & $\begin{array}{l}112 \\
70\end{array}$ & $\begin{array}{l}\text { E: } 2 / 4 / 8 \mathrm{~h} \\
\text { E: } 2 / 3 / 5 \mathrm{~h}\end{array}$ \\
\hline & TOTAL customer fixed costs & 282 & 372 & 584 & $\begin{array}{c}* A=\text { Administrative staff; } \\
\mathrm{E}=\text { Electrician }\end{array}$ \\
\hline & $\begin{array}{l}\text { Number of households in } \\
\text { building }\end{array}$ & 10 & 50 & 200 & \\
\hline & $\begin{array}{l}\text { Annual Building consumption } \\
\text { per household }(\mathrm{kWh})\end{array}$ & 1000 & 1000 & 1000 & \\
\hline
\end{tabular}




\section{Appendix B.3. Residential Building Blocks (Incl. Households)}

In this target segment, not only the general energy demand is considered, but also the energy consumption of the households. However, only the general energy demand can be controlled centrally by one FEID through the BEMS, whereas there needs to be several FEIDs to connect all the households. Additionally, there need to be individual contracts with each household.

The load profile is a combination of the two profiles above, hence it is based on $[50,51]$. Figure A6 shows this profile as an example on a typical day in shoulder season. The cost data for this customer segment are given in Table A10.

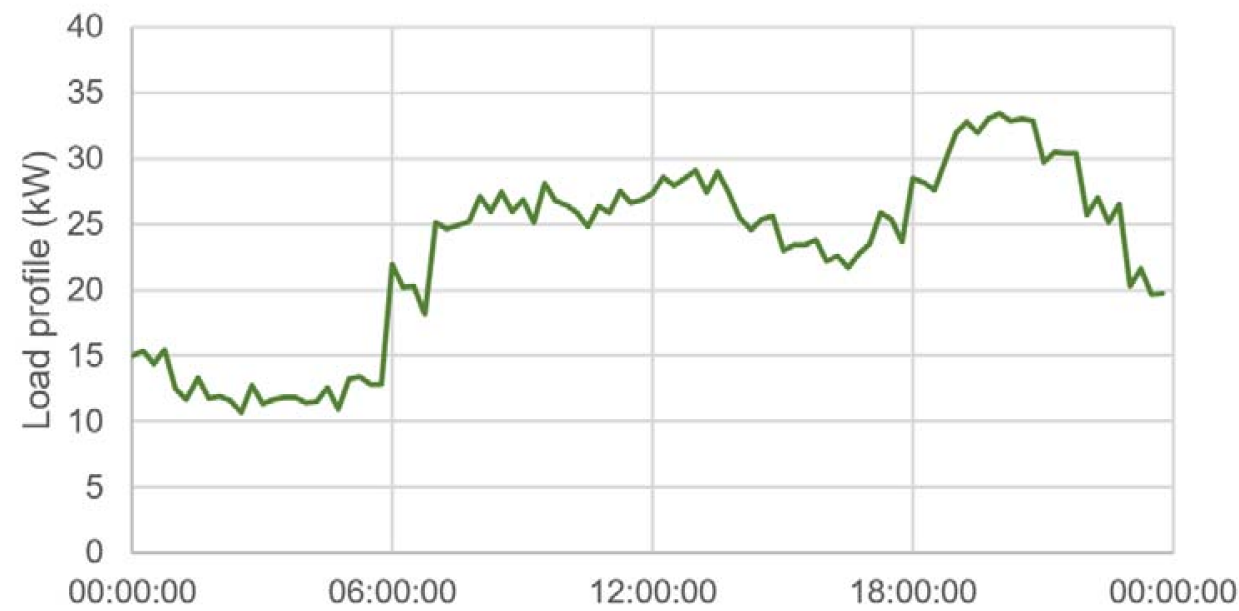

Figure A6. Load profile of the total energy demand (incl. households) of a residential building block (medium) on a day in shoulder season (9 April).

Table A10. Annual cost data for customer fixed costs (Residential building blocks incl. households).

\begin{tabular}{|c|c|c|c|c|c|}
\hline & \multirow{2}{*}{ Consumer Type } & \multicolumn{3}{|c|}{$\begin{array}{l}\text { Residential Building } \\
\text { (Incl. Households) }\end{array}$} & \multirow{4}{*}{ Quantity Required per 5-Year Period * } \\
\hline & & \multirow{2}{*}{$\begin{array}{c}S \\
40,000\end{array}$} & \multirow{2}{*}{$\begin{array}{c}M \\
200,000\end{array}$} & \multirow{2}{*}{$\begin{array}{c}\mathrm{L} \\
800,000\end{array}$} & \\
\hline & $\begin{array}{l}\text { Annual Electricity } \\
\text { Consumption (kWh) }\end{array}$ & & & & \\
\hline Category & Cost Item & $(€)$ & $(€)$ & $(€)$ & \\
\hline \multirow{4}{*}{ Investment } & FEID & 20 & 60 & 200 & 1/3/10 FEIDs \\
\hline & Other Hardware & - & - & - & \\
\hline & Establish communication & - & - & - & \\
\hline & Installation & 196 & 756 & 2912 & E: $14 / 54 / 208$ h \\
\hline \multirow{3}{*}{ Contracting } & Commercial feasibility & 150 & 470 & 1100 & A: $15 / 47 / 110$ \\
\hline & Technical feasibility & 70 & 98 & 140 & $\mathrm{E}: 5 / 7 / 10 \mathrm{~h}$ \\
\hline & Contract conclusion & 55 & 155 & 530 & A: $5.5 / 15.5 / 53 \mathrm{~h}$ \\
\hline \multirow{6}{*}{ Operation/Maintenance } & on-site trouble shooting & 28 & 56 & 112 & E: $2 / 4 / 8 \mathrm{~h}$ \\
\hline & remote maintenance & 84 & 252 & 630 & $\mathrm{E}: 6 / 18 / 45$ \\
\hline & TOTAL customer fixed costs & 603 & 1847 & 5624 & $\begin{array}{c}* \mathrm{~A}=\text { Administrative staff; } \\
\mathrm{E}=\text { Electrician }\end{array}$ \\
\hline & $\begin{array}{l}\text { Number of households in } \\
\text { building }\end{array}$ & 10 & 50 & 200 & \\
\hline & $\begin{array}{l}\text { Annual general building cons. per } \\
\text { household (kWh) }\end{array}$ & 1000 & 1000 & 1000 & \\
\hline & $\begin{array}{l}\text { Annual Consumption per } \\
\text { household }(\mathrm{kWh})\end{array}$ & 3000 & 3000 & 3000 & \\
\hline
\end{tabular}

Quantity Required per 5-Year Period*.

One FEID is considered to serve about two floors of such a building. A BEMS is considered available for the general energy demand of the building, whereas the FEID connects with household appliances through wireless connection. On-site trouble shooting is considered only for BEMS, not for households. 


\section{Appendix B.4. Office Buildings}

Here, office buildings of different sizes are considered. The load profile is based is also retrieved from the Austrian research project in [51]. A central BEMS for the relevant loads such as HVAC etc. is also considered here. Figure A7 shows this profile as an example on a typical day in shoulder season. The cost data for this customer segment are given in Table A11.

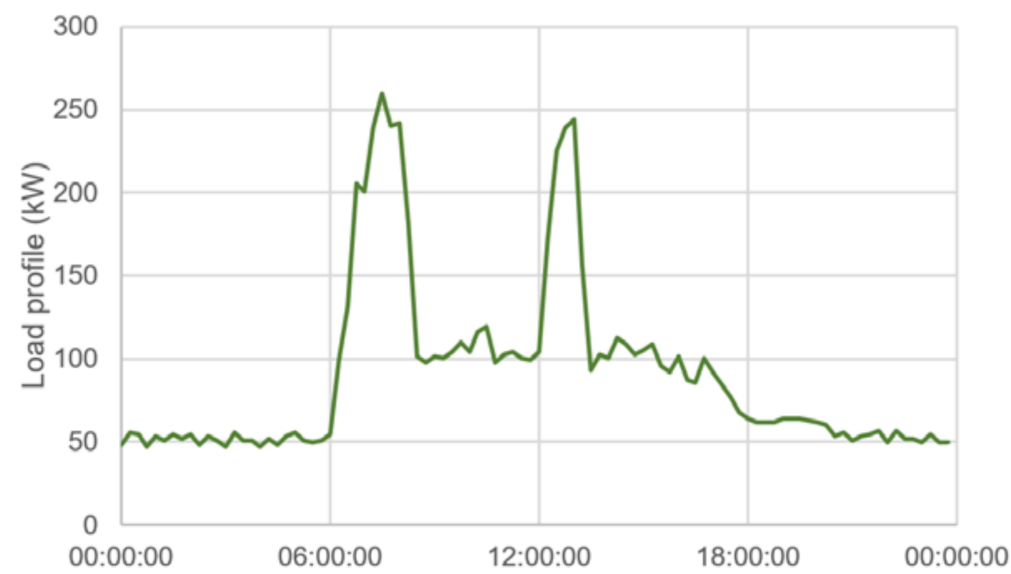

Figure A7. Load profile of an office building (medium) on a day in shoulder season (9 April).

Table A11. Annual cost data for customer fixed costs (Office building).

\begin{tabular}{|c|c|c|c|c|c|}
\hline & \multirow{2}{*}{ Consumer Type } & \multicolumn{3}{|c|}{ Office Building } & \multirow[b]{3}{*}{ Quantity Required per 5-Year Period * } \\
\hline & & \multirow{2}{*}{$\begin{array}{c}S \\
240,000\end{array}$} & \multirow{2}{*}{$\begin{array}{c}M \\
1,200,000\end{array}$} & \multirow{2}{*}{$\begin{array}{c}\mathrm{L} \\
3,200,000\end{array}$} & \\
\hline & $\begin{array}{c}\text { Annual Electricity } \\
\text { Consumption (kWh) }\end{array}$ & & & & \\
\hline Category & Cost item & $(€)$ & $(€)$ & $(€)$ & \\
\hline \multirow{4}{*}{ Investment } & FEID & 20 & 20 & 20 & 1 FEID \\
\hline & Other Hardware & - & - & - & BEMS available \\
\hline & Establish communication & - & - & - & BEMS available \\
\hline & Installation & 126 & 168 & 210 & E: $9 / 12 / 15$ h \\
\hline \multirow{3}{*}{ Contracting } & Commercial feasibility & 70 & 140 & 280 & A: $5 / 10 / 20 h$ \\
\hline & Technical feasibility & 70 & 140 & 280 & E: $5 / 10 / 20 \mathrm{~h}$ \\
\hline & Contract conclusion & 30 & 60 & 80 & A: $3 / 6 / 8 \mathrm{~h}$ \\
\hline \multirow[t]{3}{*}{ Operation/Maintenance } & on-site trouble shooting & 28 & 56 & 112 & E: $2 / 4 / 8 \mathrm{~h}$ \\
\hline & remote maintenance & 56 & 112 & 224 & E: 4/8/16 h \\
\hline & TOTAL customer fixed costs & 400 & 696 & 1206 & $\begin{aligned} * & \text { A }=\text { Administrative staff; } \\
& \mathrm{E}=\text { Electrician }\end{aligned}$ \\
\hline \multirow{2}{*}{\multicolumn{2}{|c|}{ Office space $\left(\mathrm{m}^{2}\right)$}} & 3000 & 15,000 & 40,000 & \\
\hline & & 80 & 80 & 80 & derived from $[52,53]$ \\
\hline
\end{tabular}

Quantity Required per 5-Year Period *.

Appendix B.5. Retail Buildings

Three different retail buildings are considered: A non-food shop, a supermarket and a large shopping centre. As an approximation the standard load profile G4 (shops) from [50] has been used. Figure A8 shows this profile as an example on a typical day in shoulder season. The cost data for this customer segment are given in Table A12. 


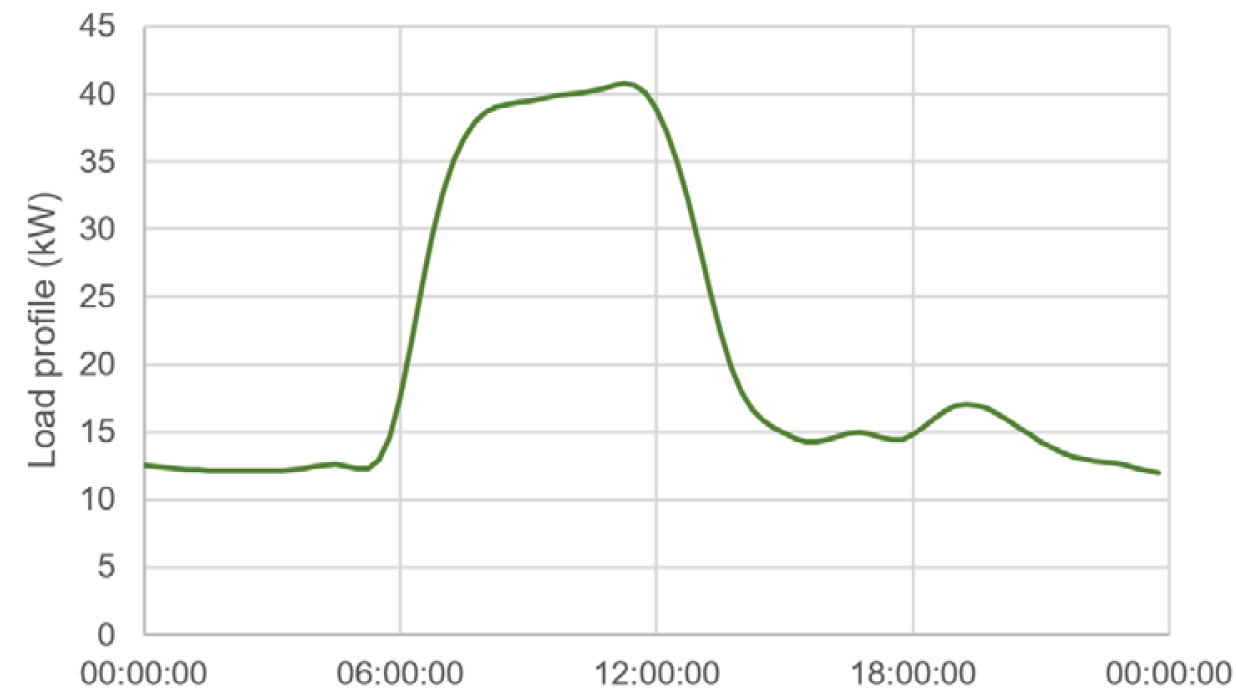

Figure A8. Load profile of a supermarket on a day in shoulder season (9 April).

Table A12. Annual cost data for customer fixed costs (Retail building).

\begin{tabular}{|c|c|c|c|c|c|}
\hline & \multirow{2}{*}{ Consumer Type } & \multicolumn{3}{|c|}{ Retail Building } & \multirow{4}{*}{ Quantity Required per 5-Year Period * } \\
\hline & & NFS & SM & SC & \\
\hline & $\begin{array}{c}\text { Annual Electricity } \\
\text { Consumption [kWh] }\end{array}$ & 72,000 & 198,000 & $12,000,000$ & \\
\hline Category & Cost Item & $(€)$ & $(€)$ & (€) & \\
\hline Investment & $\begin{array}{c}\text { FEID } \\
\text { Other Hardware } \\
\text { Establish communication } \\
\text { Installation }\end{array}$ & $\begin{array}{l}20 \\
- \\
- \\
84\end{array}$ & $\begin{array}{c}20 \\
- \\
- \\
84\end{array}$ & $\begin{array}{c}60 \\
- \\
- \\
560\end{array}$ & $\begin{array}{l}\text { 1/1/3 FEIDs } \\
\text { BEMS available } \\
\text { BEMS available } \\
\text { E: } 6 / 6 / 40 \mathrm{~h}\end{array}$ \\
\hline Contracting & $\begin{array}{l}\text { Commercial feasibility } \\
\text { Technical feasibility } \\
\text { Contract conclusion }\end{array}$ & $\begin{array}{l}50 \\
70 \\
30\end{array}$ & $\begin{array}{l}50 \\
70 \\
30\end{array}$ & $\begin{array}{l}250 \\
350 \\
150\end{array}$ & $\begin{array}{l}\text { A: } 5 / 5 / 25 h \\
\text { E: } 5 / 5 / 25 h \\
\text { A: } 3 / 3 / 15 h\end{array}$ \\
\hline \multirow[t]{4}{*}{ Operation/Maintenance } & $\begin{array}{l}\text { on-site trouble shooting } \\
\text { remote maintenance }\end{array}$ & $\begin{array}{l}28 \\
28\end{array}$ & $\begin{array}{l}28 \\
28\end{array}$ & $\begin{array}{l}280 \\
280\end{array}$ & $\begin{array}{l}\mathrm{E}: 2 / 2 / 20 \mathrm{~h} \\
\mathrm{E}: 2 / 2 / 20 \mathrm{~h}\end{array}$ \\
\hline & TOTAL customer fixed costs & 310 & 310 & 1930 & $\begin{array}{c}* \mathrm{~A}=\text { Administrative staff; } \\
\mathrm{E}=\text { Electrician }\end{array}$ \\
\hline & Retail space $\left[\mathrm{m}^{2}\right]$ & 600 & 600 & 80,000 & \\
\hline & Consumption per $\mathrm{m}^{2}$ and year & 120 & 330 & 150 & derived from [54] \\
\hline
\end{tabular}

Quantity Required per 5-Year Period *.

Appendix B.6. Electric Vehicle Charging Stations

For EV charging stations three sub-segments are considered: Individual BEV, Residential garage $(20 \mathrm{BEV})$ and Business fleet $(50 \mathrm{BEV})$. The load profiles are synthetic ones and derived from [55]. The daily load profile for such a residential garage is shown in Figure A9. The cost data for this customer segment are given in Table A13.

Compared to the other target segments, no FEID and subsequently no FEID installation works are required. This is because the charging points are considered to be already controllable. This is the case for most of the currently installed state of the art wallboxes. 


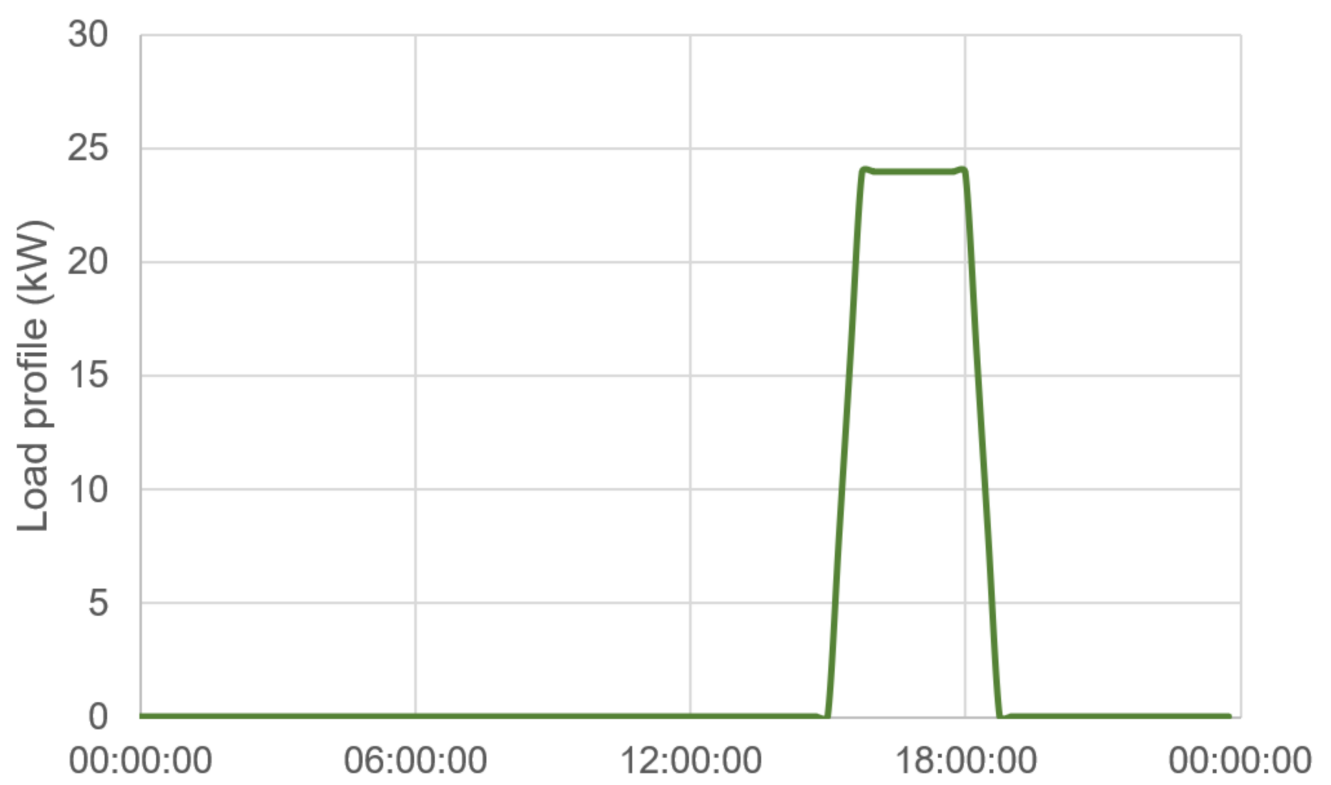

Figure A9. Synthetic daily load profile of a BEV charging station (Residential garage $20 \mathrm{BEV}$ ).

Table A13. Annual cost data for customer fixed costs (Electric vehicle charging station).

\begin{tabular}{|c|c|c|c|c|c|}
\hline & \multirow{2}{*}{ Consumer Type } & \multicolumn{3}{|c|}{ EV Charging Station } & \multirow[b]{3}{*}{ Quantity Required per 5-Year Period * } \\
\hline & & \multirow{2}{*}{$\begin{array}{c}\text { Single } \\
3000\end{array}$} & \multirow{2}{*}{$\begin{array}{c}\text { Residen. } \\
60,000\end{array}$} & \multirow{2}{*}{$\begin{array}{c}\text { Business } \\
150,000\end{array}$} & \\
\hline & $\begin{array}{c}\text { Annual Electricity } \\
\text { Consumption [kWh] }\end{array}$ & & & & \\
\hline Category & Cost Item & (€) & (€) & (€) & \\
\hline Investment & $\begin{array}{c}\text { FEID } \\
\text { Other Hardware } \\
\text { Establish communication } \\
\text { Installation }\end{array}$ & $\begin{array}{l}- \\
- \\
- \\
-\end{array}$ & $\begin{array}{l}- \\
- \\
- \\
-\end{array}$ & $\begin{array}{l}- \\
- \\
- \\
-\end{array}$ & $\begin{array}{l}\text { controllable charging point available, no } \\
\text { FEID required }\end{array}$ \\
\hline Contracting & $\begin{array}{l}\text { Commercial feasibility } \\
\text { Technical feasibility } \\
\text { Contract conclusion }\end{array}$ & $\begin{array}{l}10 \\
14 \\
10\end{array}$ & $\begin{array}{l}40 \\
56 \\
20\end{array}$ & $\begin{array}{l}40 \\
56 \\
20\end{array}$ & $\begin{array}{c}\text { A: } 1 / 4 / 4 \\
\text { E: } 1 / 4 / 4 \\
\text { A: } 1 / 2 / 2 \mathrm{~h}\end{array}$ \\
\hline \multirow[t]{2}{*}{ Operation/Maintenance } & $\begin{array}{l}\text { on-site trouble shooting } \\
\text { remote maintenance }\end{array}$ & $\begin{array}{c}0 \\
14\end{array}$ & $\begin{array}{c}0 \\
28\end{array}$ & $\begin{array}{l}56 \\
84\end{array}$ & $\begin{array}{l}\text { E: } 0 / 0 / 4 \mathrm{~h} \\
\text { E: } 1 / 2 / 6 \mathrm{~h}\end{array}$ \\
\hline & TOTAL customer fixed costs & 48 & 144 & 256 & ${ }^{*} \mathrm{~A}=\underset{\mathrm{E}=\text { Electrician }}{\text { Administrative staff; }}$ \\
\hline \multicolumn{2}{|c|}{$\begin{array}{c}\text { Number of BEVs } \\
\text { Consumption [kWh] per year and BEV } \\
\text { Kilometres per year and BEV } \\
\text { Consumption [kWh] per } 100 \mathrm{~km}\end{array}$} & $\begin{array}{c}1 \\
3000 \\
15,000 \\
20\end{array}$ & $\begin{array}{c}20 \\
3000 \\
15,000 \\
20\end{array}$ & $\begin{array}{c}50 \\
3000 \\
15,000 \\
20\end{array}$ & \\
\hline
\end{tabular}

Quantity Required per 5-Year Period *.

Appendix B.7. Overhead Costs

Besides the customer fixed costs, also overhead costs are considered in the cost calculation. The overhead costs apply to the service provider as a whole, such as an aggregator or FLESCO. For this calculation, the overhead costs are considered as a function of the portfolio size, as shown in Table A14. However, as a simplification there are the same for all customer segments.

The staff costs include engineering, market trading, customer service, customer acquisition, finance, etc. that is not included with a specific project and therefore does not fall under the customer fixed costs mentioned above. 
Table A14. Annual overhead cost data.

\begin{tabular}{|c|c|c|c|c|}
\hline Number of Customers & 1000 & 10,000 & 10,0000 & \\
\hline Cost Item & (EUR) & (EUR) & (EUR) & Assumption \\
\hline IT infrastructure & 3000 & 6000 & 12,000 & $250 / 500 / 1000$ EUR server costs per month \\
\hline licenses & 2400 & 24,000 & 240,000 & 0.2 EUR per customer per month \\
\hline Staff costs & 480,000 & 600,000 & 900,000 & $8 / 10 / 15$ employees, average $60,000 \mathrm{EUR} /$ person/year \\
\hline Office rent & 25,200 & 29,400 & 63,000 & office size: $60,70,150 \mathrm{~m}^{2}$; average $35 \mathrm{EUR} / \mathrm{m}^{2} / \mathrm{month}$ \\
\hline TOTAL overhead & 510,600 & 659,400 & $1,215,000$ & \\
\hline
\end{tabular}

\section{References}

1. European Commission. Incorporing Demand Side Flexibility, in Particular Demand Response, in Electricity Markets; European Commission: Brussels, Belgium, 2013.

2. Ribó-Pérez, D.; Larrosa-López, L.; Pecondón-Tricas, D.; Alcázar-Ortega, M. A Critical Review of Demand Response Products as Resource for Ancillary Services: International Experience and Policy Recommendations. Energies 2021, 14, 846. [CrossRef]

3. Directive 2012/27/EU of the European Parliament and of the Council of 25 October 2012 on Energy Efficiency, Amending Directives 2009/125/EC and 2010/30/EU and Repealing Directives 2004/8/EC and 2006/32; European Parliament: Brussels, Belgium, 2012.

4. Zancanella, P.; Bertoldi, P.; Boza-Kiss, B. Why Is Demand Response Not Implemented in the EU? Status of Demand Response and Recommendations to Allow Demand Response to Be Fully Integrated in Energy Markets. In Proceedings of the ECEEE 2017 Summer Study on Energy Efficiency, Consumption, Efficiency and Limits, Toulon/Hyères, France, 29 May-3 June 2017.

5. Willems, B.; Zhou, J. The Clean Energy Package and Demand Response: Setting Correct Incentives. Energies $2020,13,5672$. [CrossRef]

6. Federal Energy Regulatory Commission (FERC). FERC Order No. 2222: Fact Sheet 2020; Federal Energy Regulatory Commission (FERC): Washington, DC, USA, 2020.

7. Behi, B.; Baniasadi, A.; Arefi, A.; Gorjy, A.; Jennings, P.; Pivrikas, A. Cost-Benefit Analysis of a Virtual Power Plant Including Solar PV, Flow Battery, Heat Pump, and Demand Management: A Western Australian Case Study. Energies 2020, 13, 2614. [CrossRef]

8. Li, W.; Xu, P.; Lu, X.; Wang, H.; Pang, Z. Electricity demand response in China: Status, feasible market schemes and pilots. Energy 2016, 114, 981-994. [CrossRef]

9. Parrish, B.; Heptonstall, P.; Gross, R.; Sovacool, B.K. A systematic review of motivations, enablers and barriers for consumer engagement with residential demand response. Energy Policy 2020, 138, 111221. [CrossRef]

10. Pallonetto, F.; De Rosa, M.; D'Ettorre, F.; Finn, D.P. On the assessment and control optimisation of demand response programs in residential buildings. Renew. Sustain. Energy Rev. 2020, 127, 109861. [CrossRef]

11. Tzovaras, D. About DELTA. Available online: https://www.delta-h2020.eu/ (accessed on 21 September 2021).

12. Paterakis, N.; Erdinç, O.; Catalão, J.P.S. An overview of Demand Response: Key-elements and international experience. Renew. Sustain. Energy Rev. 2017, 69, 871-891. [CrossRef]

13. Kwac, J.; Rajagopal, R. Data-Driven Targeting of Customers for Demand Response. IEEE Trans. Smart Grid 2016, 7, $2199-2207$. [CrossRef]

14. Qi, N.; Cheng, L.; Xu, H.; Wu, K.; Li, X.; Wang, Y.; Liu, R. Smart meter data-driven evaluation of operational demand response potential of residential air conditioning loads. Appl. Energy 2020, 279, 115708. [CrossRef]

15. Antonopoulos, I.; Robu, V.; Couraud, B.; Flynn, D. Data-driven modelling of energy demand response behaviour based on a large-scale residential trial. Energy AI 2021, 4, 100071. [CrossRef]

16. Hamwi, M.; Lizarralde, I.; Legardeur, J. Demand response business model canvas: A tool for flexibility creation in the electricity markets. J. Clean. Prod. 2021, 282, 124539. [CrossRef]

17. Osterwalder, A.; Pigneur, Y. Business Model Generation: A Handbook for Visionaries, Game Changers, and Challengers; Wiley: Hoboken, NJ, USA, 2010; ISBN 978-0-470-90103-8.

18. SEDC. Mapping Demand Response in Europe Today; Smart Energy Demand Coalition: Brussels, Belgium, 2014.

19. Villar, J.; Bessa, R.; Matos, M. Flexibility products and markets: Literature review. Electr. Power Syst. Res. 2018, 154, 329-340. [CrossRef]

20. Behrangrad, M. A review of demand side management business models in the electricity market. Renew. Sustain. Energy Rev. 2015, 47, 270-283. [CrossRef]

21. Van der Veen, A.; Van der Laan, M.; De Heer, H.; Klaassen, E.; Van den Reek, W. Flexibility Value Chain; USEF Foundation: Arnhem, The Netherlands, 2018.

22. ENTSO-E. Market Design for Demand Side Response-Policy Paper; European Network of Transmission System Operators for Electricity: Brussels, Belgium, 2015.

23. Lu, X.; Li, K.; Xu, H.; Wang, F.; Zhou, Z.; Zhang, Y. Fundamentals and business model for resource aggregator of demand response in electricity markets. Energy 2020, 204, 117885. [CrossRef]

24. Ponds, K.T.; Arefi, A.; Sayigh, A.; Ledwich, G. Aggregator of Demand Response for Renewable Integration and Customer Engagement: Strengths, Weaknesses, Opportunities, and Threats. Energies 2018, 11, 2391. [CrossRef]

25. De Heer, H.; Van der Laan, M. USEF: Workstream on Aggregator Implementation Models; USEF Foundation: Arnhem, The Netherlands, 2017. 
26. Yu, M.; Hong, S.H.; Kim, J.B. Incentive-based demand response approach for aggregated demand side participation. In Proceedings of the 2016 IEEE International Conference on Smart Grid Communications (SmartGridComm), Sydney, Australia, 6-9 November 2016; IEEE: Sydney, Australia, 2016; pp. 51-56.

27. USEF. USEF: The Framework Explained 2015; USEF Foundation: Arnhem, The Netherlands, 2015.

28. Joint Research Center Energy Service Companies (ESCOs). Available online: https://e3p.jrc.ec.europa.eu/communities / energyservice-companies (accessed on 21 September 2021).

29. Leutgöb, K.; Amann, C.; Tzovaras, D.; Ioannidis, D. New Business Models Enabling Higher Flexibility on Energy Markets. In Proceedings of the ECEEE 2019 Summer Study on Energy Efficiency: Is Efficient Sufficient? Toulon/Hyères, France, 3-8 June 2019.

30. Ma, Z.; Billanes, J.; Jørgensen, B. Aggregation Potentials for Buildings—Business Models of Demand Response and Virtual Power Plants. Energies 2017, 10, 1646. [CrossRef]

31. Energati NOVICE Project Proposes New Energy Efficiency Business Model. Available online: https:/ /www.engerati.com/energyretail/novice-project-proposes-new-energy-efficiency-business-model/ (accessed on 21 September 2021).

32. Specht, J.M.; Madlener, R. Energy Supplier 2.0: A conceptual business model for energy suppliers aggregating flexible distributed assets and policy issues raised. Energy Policy 2019, 135, 110911. [CrossRef]

33. Iria, J.; Soares, F.; Matos, M. Optimal bidding strategy for an aggregator of prosumers in energy and secondary reserve markets. Appl. Energy 2019, 238, 1361-1372. [CrossRef]

34. Iria, J.P.; Soares, F.J.; Matos, M.A. Trading Small Prosumers Flexibility in the Energy and Tertiary Reserve Markets. IEEE Trans. Smart Grid 2019, 10, 2371-2382. [CrossRef]

35. Zepter, J.M.; Lüth, A.; Crespo del Granado, P.; Egging, R. Prosumer integration in wholesale electricity markets: Synergies of peer-to-peer trade and residential storage. Energy Build. 2019, 184, 163-176. [CrossRef]

36. Bertoldi, P.; Zancanella, P.; Boza-Kiss, B. Demand Response Status in EU Member States; Joint Research Center: Ispra, Italy, 2016.

37. ENTSO-E Prices of Activated Balancing Energy. Available online: https://www.entsoe.eu/network_codes/eb/ (accessed on 14 June 2021).

38. National Grid FFR Market Information and Tender Reports. Available online: https://www.nationalgrideso.com/industryinformation/balancing-services/frequency-response-services / firm-frequency-response-ffr?market-information (accessed on 5 August 2021).

39. National Grid. Firm Frequency Response-Frequently Asked Questions v1.3; National Grid: Warwick, UK, 2017.

40. ENTSO-E Day-Ahead Prices. Available online: https://transparency.entsoe.eu/ (accessed on 14 June 2021).

41. Nord Pool AS Market Data. Available online: https://www.nordpoolgroup.com/Market-data1/\#/n2ex/table (accessed on 16 July 2021).

42. VITO; Viegand \& Maagøe; Armines; Bonn University. Wuppertal Institut Ecodesign Preparatory Study on Smart Appliances (Lot 33)-Task 7 Report Policy and Scenario Analysis; Flemish Institute for Technological Research NV: Boeretang, Belgium, 2018.

43. The Mobility House Vehicle-to-Grid. Available online: https://www.mobilityhouse.com/int_en/vehicle-to-grid (accessed on 20 October 2021).

44. Austrian Power Grid Balancing Statistics 2020. Available online: https:/ / www.apg.at/ (accessed on 16 July 2021).

45. OFGEM Your Bill Breakdown. Available online: https://www.ofgem.gov.uk/energy-advice-households/costs-your-energy-bill (accessed on 5 August 2021).

46. Angebote Strom, Spotty Smart Energy Partner GmbH. Available online: https:/ / www.spottyenergie.at (accessed on 16 July 2021).

47. karriere.at Gehaltsvergleich Büroangestellte/r. Available online: https://www.karriere.at/gehalt/b\%C3\%BCroangestellter (accessed on 20 July 2021).

48. Eurostat Wages and Labour Costs. Available online: https:/ / ec.europa.eu/eurostat/statistics-explained/index.php?title=Wages_ and_labour_costs (accessed on 20 July 2021).

49. AK Wien Preisvergleich Handwerker in Wien. Available online: https:/ / wien.arbeiterkammer.at/beratung/konsumentenschutz/ einkaufundrecht/preisvergleich_handwerker_wien.html (accessed on 20 July 2021).

50. BDEW Standardlastprofile Strom. Available online: https://www.bdew.de/energie/standardlastprofile-strom/ (accessed on 20 July 2021).

51. Lampersberger, P. DeLight Monitoring-Demo Light Impact-Monitoring and Metrological Investigation of Energy-Efficient Buildings. Available online: https:// nachhaltigwirtschaften.at/en/sdz/projects/delight-monitoring.php (accessed on 20 July 2021).

52. D'Agostino, D.; Cuniberti, B.; Bertoldi, P. Energy consumption and efficiency technology measures in European non-residential buildings. Energy Build. 2017, 153, 72-86. [CrossRef]

53. Benke, G.; Leutgöb, K. Energieverbrauch Im Dienstleistungssektor-Kennwerte Und Hochrechnung; E7 Energy Innovation \& Engineering: Wien, Austria, 2012.

54. Statista Stromverbrauch je Quadratmeter Verkaufsfläche im Deutschsprachigen Einzelhandel in den Jahren 2013 und 2015. Available online: https:/ / de.statista.com/statistik/daten/studie/372110/umfrage/stromverbrauch-je-quadratmeter-verkaufsflaecheim-deutschsprachigen-einzelhandel/ (accessed on 2 August 2021).

55. Preßmair, G.; Lampersberger, P. Anschlussleistung Für Wohnhausanlagen Mit E-Ladeinfrastruktur. In Proceedings of the Symposium Energieinnovation, Graz, Austria, 13 February 2020. 